\title{
Experimental study on configuration optimization of floating breakwaters
}

\author{
Chun-Yan Jía, Xiang Chen ${ }^{\mathrm{a}, \mathrm{b}}$, Jie Cui ${ }^{\mathrm{a}, *}$, Oleg Gaidai ${ }^{\mathrm{a}}$, Atilla Incecik
}

${ }^{a}$ School of Naval Architecture and Ocean Engineering, Jiangsu University of Science and Technology, Zhenjiang 212003, China

${ }^{\mathrm{b}}$ School of Naval Architecture, Ocean and Civil Engineering, Shanghai Jiao Tong University, Shanghai 200240, China

${ }^{c}$ Department of Naval Architecture, Ocean and Marine Engineering, University of Strathclyde, Glasgow, UK

Corresponding Author:

Jie Cui

Tel: +86051189983009

Mobile: +8615050856887

Fax: +86051184404433

E-mail: cuijie2006@hotmail.com

\begin{abstract}
In this paper, four types of floating breakwaters $(\mathrm{FB})$ are proposed: cylindrical floating breakwater (CFB), porous floating breakwater (PFB), mesh cage floating breakwaters I (MCFB I ) and mesh cage floating breakwaters $\amalg$ (MCFB $\amalg)$. The hydrodynamic performance of each type has been tested to demonstrate the most effective configuration of wave attenuation. The experiment was conducted in a wave flume under regular wave. The incident and transmitted waves, the tensions on the mooring lines and the motion responses of all floating breakwaters for four types were measured. It is shown that all proposed types of floating breakwaters can effectively reduce wave transmission. MCFB I type is seen to yield the most wave attenuation among four proposed breakwater types.
\end{abstract}

Keywords: Floating breakwater; Model experiments; Cylindrical; Porous; Mesh cage

\section{Introduction}


Floating breakwater is the harbor protection structure that has a purpose the of attenuating transmitted wave. Transmitted wave energy reduction is critical for the safety of other floating structures and ships.

Comparatively to the traditional bottom-fixed breakwater, the floating breakwater type has some advantages. Firstly, the cost of traditional bottom-fixed breakwater increases rapidly with the increase of water depth, while floating breakwater offers a cheaper solution. Secondly, floating breakwater is friendly to the ocean environment such as water exchange. And floating breakwater can be installed and disassembled easily.

In 1811, the British built a wood floating breakwater which is regarded as the first around world in Plymouth Harbor. From then on, many floating breakwaters were used to protect harbors. And they are proved the effect of decreasing wave. So, people become aware of the advantages of floating breakwater and want to find a more effective configuration.

The most common configuration of floating breakwater is a single pontoon. (N. Drimer et al., 1992; S. A. Sannasiraj et al., 1998; A. G. Abul-Azm et al., 2000; E. V. Koutandos et al., 2004; Mohamed R. Gesraha, 2006; Ghassan Elchahal et al., 2008; Fang he et al., 2012, 2013; Wei Peng et al., 2013; A. S. Koraima and O. S. Rageh., 2013)

Based on single pontoon, double pontoons can increase inertia without adding total weight by increasing the distance between two pontoons. Whether single or double, the main wave attenuation is reflection. But for double pontoon, it can also reduce wave between two floating bodies. A. N. Williams and A. G. Abul-Azm investigated theoretically the hydrodynamic properties of a dual pontoon floating breakwater consisting of a pair of floating cylinders of rectangular section, connected by a rigid deck. The results reveal that the draft and spacing of the pontoons and the mooring line stiffness influence strongly the wave reflection properties of the structure. At 2006, Md. Ataur Rahman et al. investigated a two-dimensional numerical estimation method of calculating dynamics of a pontoon type submerged floating breakwater and the forces acting on its mooring lines due to the wave action. Comparing the numerical with the experimental results, the validity of the numerical model and the good performance on wave energy dissipation is confirmed. In addition, the 
results illustrated that the clear space has a great effect upon responses of the structure; it not only changes the natural frequency of the structure, but causes heave motion to have a peak response in high frequency range. And a dual pontoon floating structure with a fish net for cage aquaculture is studied (Hung-Jie Tang et al., 2011). The resonant responses of roll and tension RAO generally decrease as net depth increases, but the magnitudes of these changes are very small. And the influence of net width on the dynamic motions is not only large, but also more complicated than the influence of net depth.

No matter single pontoon or double pontoon, they are all reflective structure. Other floating breakwaters are dissipative structures, where a certain amount of the incident energy is destroyed by fiction, turbulence, etc. H.Y. Wang and Z.C.Sun conducted a experimental study of a porous floating breakwater at 2010. The transmission coefficient decreased with the increase of both the width of breakwater and initial mooring force, and the value of the dissipation of wave energy increases with the increase of the width of breakwater. Another experimental study on the performance characteristics of porous perpendicular pipe breakwaters was conducted by Ruey-Syan Shih at 2012. They found that performance is greatly influenced by increased incident wave heights for shorter waves under identical pipe diameter and longer pipe is more efficient in reducing the reflection coefficient.

The traditional structures are built of concrete. They will suffer great wave stress and easy to be destroyed. In addition, in order to reduce the cost of floating breakwater, the flexible structure is applied. At 2008, G.H. Dong et al. conducted physical model tests to measure the wave transmission coefficient of the broad-net floating breakwater. The experimental results show that the board-net floating breakwater, which is a simple and inexpensive type of structure, can effectively protect fish and fish cages and may be adopted for aquaculture engineering in deep-water regions. Interaction of surface gravity waves with multiple vertically moored surface-piercing membrane breakwaters in finite water depth is analyzed based on the linearized theory of water waves (D. Karmakar et al., 2012). The comparison of the results for various fixed and moored edge conditions is analyzed for reflection and transmission coefficients. The conclusion showed that in the case of single 
surface-piercing membrane, with the increase in the length of the membrane and tension of the membrane the wave reflection increases and the presence of multiple floating breakwater helps in the reduction of wave height in the transmitted region. Arkal Vittal Hegde et al. (2008) studied the mooring forces in horizontal interlaced moored floating pipe breakwater with three layers. They found that the maximum force in the seaward side mooring for model with $\mathrm{S} / \mathrm{D}=4$ is lower compared to that for the breakwater model with $\mathrm{S} / \mathrm{D}=2$ ( $\mathrm{S}$ is the spacing of pipes and $\mathrm{D}$ the diameter of pipe). A.S. Koraim (2013) conducted a new type of breakwater which consisted of one or more horizontal rows of half pipes suspended on supporting piles. With the number of rows increasing, the efficiency of breakwaters increases.

This paper introduces design of four different FB models. Experimental study was conducted to measure the effect of wave attenuation and hydrodynamic performance of each model. By analyzing experimental results, the best configuration is chosen.

\section{Configuration design}

The model 1 introduces a cylindrical based double pontoon FB. Double pontoons can increase inertia to reduce motion responses. In addition, the use of double pontoons type increases the width of floating breakwater. Using the type of double pontoons, one can build wider floating breakwater to improve wave attenuation with same materials. Authors propose cylindrical FB design consisting of two $4 \mathrm{~m}$ diameter $\times 15.2 \mathrm{~m}$ long cylinders and nine $0.4 \mathrm{~m}$ diameter $\times 2 \mathrm{~m}$ long cylinders in Fig. 1 . The material of cylinders is reinforced concrete. We call it cylindrical floating breakwater.

The model 2 is porous FB. The porous FB are well studied and proved to be efficient in wave attenuation. Under the wave and sun action, the traditional concrete FB is easy to crack. Once water flows into the enclosed spaces of FB, FB will sink. Authors introduce new design of porous FB that is secured from water leakage due to the structure destruction. Two vertical plates, three longitudinal plates, three transverse plates and eight columns are connected together to form eight independent spaces. The holes are placed at the top vertical plate and top parts of longitudinal and transverse plates. Four hollow rubber floating bodies 
are stuffed into the lower four spaces to provide buoyancy. These underwater floating bodies have longer fatigue life. Once one of these is damaged, others can still provide enough buoyancy. This is called as porous floating breakwater. The main structure of model 2 is shown in Fig. 2.

The model 3 introduces mesh cage FB, type I . Cage structure has lower production cost than two FB models introduced above. As shown in Fig. 3, the main frame of model 3 is made up of steel. Two hollow rubber floating bodies are placed at the front and back of floating breakwater to provide buoyance and reflect wave. Between two bodies, meshes are installed on the steel to dissipate wave.

The model 4 introduces mesh cage FB, type I in Fig. 4. In order to increase fatigue life, the rubber floating body is placed below the wave surface based on steel frame. Meshes are installed at the top part of the frame.

\section{Experimental setup}

3.1 Experimental facilities and equipment

Figs. 5-6 present experimental setup. Authors have conducted series of experiments in the wave flume of the Hydraulics Modeling Laboratory of Ocean University of China, suitable for two-dimensional hydrodynamic tests. The wave flume is $60 \mathrm{~m}$ long, $3.0 \mathrm{~m}$ wide and $1.5 \mathrm{~m}$ deep. For this study, the flume width was reduced to $0.8 \mathrm{~m}$, in accordance with experimental scale. A piston-type wave-maker was installed at one end of the flume. The wave-absorbing beach was located at the opposite end to reduce the wave reflection.

As shown in Fig. 5, the model is moored by catenary lines. Each mooring line is made of stainless steel and has a length of $1.6 \mathrm{~m}$ with a line density of $0.63 \mathrm{~kg} / \mathrm{m}$. Two one-dimensional strain gauges are used to record the mooring line forces.

Measurements of the incident wave height and the transmitted wave height is done by placing 5 wave gauges. The distances between the wave gauges are listed in Table 1 .

\subsection{Experimental models}

In order to find the most efficient configuration, four FB types are analyzed in this paper. For the purpose of consistency of model comparison, the main dimensions of each 
model are chosen to be the same.

Model 1 is Cylindrical FB made of two $0.2 \mathrm{~m}$ diameter cylinders and nine $0.02 \mathrm{~m}$ diameter cylinders in Fig. 9.

Model 2 is Porous FB which is shown in Fig. 10. Three porous longitudinal plates, three porous transverse plates, two porous vertical plates and eight columns are combined into model 2 which the topper vertical plates are porous.

As shown in Fig. 11-12, Model 3 and 4 are Mesh Cage FBs. The frames of Model 3 and 4 are all fabricated with steels. Two floating bodies are placed at the front and the back of Model 3. And meshes are placed between the floating bodies. One floating body is placed at the bottom of Model 4 and meshes are placed at the top part. Main parameters of four models are listed in Table 2.

3.3 Model scale and experimental conditions

In accordance with the dimensions of experimental facilities and the tested wave conditions, the scale is 1:20.

In all experiments, the water depth is $1 \mathrm{~m}$. Therefore, the prototype water depth is $20 \mathrm{~m}$. The regular wave periods range from 0.9 to $1.4 \mathrm{~s}$, and the wave heights from 0.1 to $0.2 \mathrm{~m}$. Details are presented in Table 3.

\section{Results and discussions}

This paper employs the two-point method presented by Goda and Suzuki (1976). This method separates the amplitudes of incident wave $\left(A_{i}\right)$ and reflected wave $\left(A_{r}\right)$ by the measured surface elevations. One can separate the amplitude of incident wave $\left(\mathrm{A}_{\mathrm{i}}\right)$ from WG2-3 and obtain the amplitude of transmitted wave $\left(A_{t}\right)$ from WG4-5. The transmission coefficient $\left(\mathrm{K}_{\mathrm{t}}\right)$ is defined as $\mathrm{A}_{t} / \mathrm{A}_{\mathrm{i}}$.

Besides, the amplitude of each motion response was monitored by the 6-DOF camera installed at the front of FB. The peak values of forces acting on the windward and leeward lines were recorded by strain gauges.

\subsection{Wave transmission coefficients}

Fig. 11 shows the relationship between the transmission coefficients and the wave height for the four models when the wave period is $1.0 \mathrm{~s}$. 
As shown in Fig. 11, the transmission coefficients of Model 1 and 3 slightly decrease with the increase of wave height. As we know, higher wave leads intense movement that will improve wave reflection. And more wave energy is dissipated by intense movement. $\mathrm{K}_{\mathrm{t}}$ of Model 2 increases with the wave height increases. For Model 2, due to porosity of the plates, higher wave will lead more waves to flow into top part of model. This part of water adds the weight of Model 2 so that a majority of Model 2 will sink under waterline. Therefore more waves will be transmitted beyond Model 2.

$\mathrm{K}_{\mathrm{t}}$ of Model 4 is nearly unchanged. Since higher wave results in greater reflection and dissipation, more waves will transmit beyond the floating body of Model 4.

Comparing four models, transmission coefficient $\mathrm{K}_{\mathrm{t}}$ is found to be smallest for the Model 3 and largest the Model 1.

Fig. 12-13 reveal changes in transmission coefficients against the wave period for the four models for the wave height is $0.15 \mathrm{~m}$ and $0.2 \mathrm{~m}$, respectively.

As seen in Figs. 12-13, the transmission coefficients of all models increase with the increase of the wave period. The Model 3 transmission coefficient $K_{t}$ is found to be the smallest. As $\mathrm{H}=0.15 \mathrm{~m}$ and $\mathrm{T}=0.9 \mathrm{~s}, \mathrm{~K}_{\mathrm{t}}$ of Model 3 is about $20 \%$ smaller than for the other three models.

The windward area of Model 3 is largest among all four models, therefore it exhibits stronger wave reflection. In addition, wave energy is dissipated by destroying particle orbit and the flow of water through the mesh hole of Model 3.

Above all, Model 3 shows more wave attenuation than other 3 models.

\subsection{Motion responses}

With the wave period being 1.0 s, Figs. 14-16 show the four models the variation of motion responses with the wave height. Figs. 17-22 show the four models the variations of motion responses with the wave period, given the wave height $0.15 \mathrm{~m}$ and $0.2 \mathrm{~m}$, respectively.

As shown in Figs. 14-16, the motion responses of all models increase with the increase of the wave height. Comparing between four models, the heave and roll motions of Model 2 are the smallest. The reason is the Model 2 porous plates sinking. The latter will result in the 
increase of weight, inertia and damping for Model 2. Therefore these changes are damping the heave and roll motions. The sway motion of Model 1 is the smallest. At the same time, the heave motion of Model 1 is the largest. And the responses of Model 3 and 4 are nearly similar.

As seen in Figs. 17-18 and 20-21, the sway and heave motions increase with the increase of the wave period. The sway motion of Model 1 is still the smallest. But the growth rate of sway motion is rapid for Model 1. Observing the results carefully, when wave period is small, the sway motion of Model 1 is far smaller than other three models. But $\mathrm{T}$ is up to $1.4 \mathrm{~s}$, the sway motion of Model 1 is close to other three models.

Figs. 19 and 22 show the four models the variation of roll motion with the wave period. When $\mathrm{T}=0.15 \mathrm{~m}$, the roll motions of Model 3 and 4 decrease with the increase of wave period, but Model 1 is nearly unchanged. As $\mathrm{H}=0.2 \mathrm{~m}$, the roll motion of Model 1 increase with the increase of wave period, but Model 3 and 4 are nearly unchanged.

Overall, the sway motion of Model 1 is the smallest and the heave and roll motions of Model 2 are the smallest. The motion responses of Model 3 and 4 are same.

\subsection{Mooring forces}

Figs. 23-24 show the variations of mooring forces with the increase of wave height for the four models when the wave period is $1.0 \mathrm{~s}$.

As shown in Figs. 23-24, the mooring forces of Model 1, 3, 4 increase with the increase of the wave height and of Model 2 are nearly unchanged. The mooring forces of Model 1 are the biggest among four models. The higher the wave is, the greater the force acting on model is. For model 2, the sinking causes the mooring lines slack. In addition, the slight movement causes decrease of the mooring forces.

Figs. 25-28 reveal changes of mooring forces against the wave period for the four models as the wave height is $0.15 \mathrm{~m}$ and $0.2 \mathrm{~m}$, respectively.

For force acting on the windward line, different model reveals different change rule. As $\mathrm{T}=1.2 \mathrm{~s}, \mathrm{~F}_{\mathrm{w}}$ of Model 1 is the smallest. The $\mathrm{F}_{\mathrm{w}} \mathrm{S}$ of Model 2 and 4 increase with the increase of wave period. When $\mathrm{H}=0.15 \mathrm{~m}, \mathrm{~F}_{\mathrm{w}}$ of Model 3 decreases when the wave period increasing. But as $\mathrm{H}=0.2 \mathrm{~m}, \mathrm{~F}_{\mathrm{w}}$ of Model 3 is nearly unchanged. 
For the force acting on the leeward line, $F_{1}$ of Model 2 is nearly unchanged and other three models with the increase of wave period.

Comparing between four models, the mooring forces of Model 2 are the smallest.

\section{Conclusions}

In this paper, four types of breakwater are proposed. A series of regular wave experiments were carried out to find the configuration that gives most wave attenuation. According to results, the following conclusions are drawn:

1) All four models reduce transmitted wave. Due to the bigger windward area and the mesh dissipation, mesh cage type I FB (Model 3) reflects and dissipates wave more efficiently than other three models.

2) Porous type FB (Model 2) allows allow water to flow into the top part of FB so that causes FB sink. Therefore wave transmission is increased. But in this way, the weight, inertia and damping of porous floating breakwater are improved so much that the heave and roll motions are smaller than other types. The mooring forces of porous floating breakwater are found to be the smallest among all four type FBs.

3) The cylindrical type FB (Model 1) exhibits smallest wave attenuation among all four type FBs. In addition, the sway motion and mooring forces of it are the biggest.

4) The hollow top structure of mesh cage type $\Pi$ (Model 4) is same as porous type FB. These two types all allow water flow into the top part of FB so that FB will sink under waterline. So, wave attenuation and mooring forces of them are similar.

Above all, the mesh cage type $I$ is the best type to wave attenuation and the motion responses and the mooring forces of porous type are the smallest. Maybe we can use the porous structure based on mesh cage type $I$ is found to be most promising model among all four models studied in this paper. But it is difficult to place holes on rubber bodies. A further research is needed to find a better configuration of floating breakwater.

\section{Acknowledgment}

This study was supported financially by the National Natural Science Foundation of China, China (Grant no. 51579122, 51379095, 51409129) and the National Basic Research 
Program of China (973 Program; Grant no. 2013CB3610 0).

\section{Reference}

Abul-Azm, A.G., Gesraha, M.R., 2000. Approximation to the hydrodynamics of floating pontoons under oblique waves. Ocean Engineering 27, 365-384.

Dong, G..H., Zheng, Y.N., Li, Y.C., Teng, B., et.al., 2008. Experiments on Wave Transmission Coefficients of Floating Breakwaters. Ocean Engineering 35, 931-938.

Drimer, N., Agnon, Y., Stiassnie, M., 1992. A simplified analytical model for a floating breakwater in water of finite depth. Applied Ocean Research 14, 33-41.

Ghassan, E., Rafic, Y., Pascal, L., 2008. The effects of reflection coefficient of the harbour sidewall on the performance of floating breakwaters. Ocean Engineering 35, 1102-1112.

Goda, Y., Suzuki, Y., 1976. Estimation of incident and reflected waves in random wave experiments. Proceedings of the 15th International Conference on Coastal Engineering. ASCE, 828-845.

Sannasiraj, S.A., Sundar V., Sundaravadivelu R., 1998. Mooring forces and motion responses of pontoon-type floating breakwaters. Ocean Engineering 25 (1), 27-48.

Hegde, A.V., Kamath, K., Deepak, J.C., 2008. Mooring Forces in Horizontal Interlaced Moored Floating Pipe Breakwater with Three Layers. Ocean Engineering 35, 165-173.

He F., Huang, Z.H., Adrian, W.-K.L., 2012. Hydrodynamic Performance of a Rectangular Floating Breakwater with and without Pneumatic Chambers: An Experimental Study. Ocean Engineering 51, $16-27$.

He F., Huang, Z.H., Adrian, W.-K.L., 2013. An experimental study of a floating breakwater with asymmetric pneumatic chambers for wave energy extraction. Applied Energy 106, 222-231.

Koraim, A.S., 2013. Hydrodynamic Efficiency of Suspended Horizontal Rows of Half Pipes Used as a New Type Breakwater. Ocean Engineering 64, 1-22.

Koraima, A. S., Rageh, O. S., 2013. Effect of Under Connected Plates on the Hydrodynamic Efficiency of the Floating Breakwater, China Ocean Engineering 28 (3), 349-362.

Karmakar, D., Bhattacharjee, J., Soares, C.G., 2012. Scattering of Gravity Waves by Multiple Surface-piercing Floating Membrane. Applied Ocean Research 39: 40-52.

Koutandos, E.V., Karambas, Th.V., Koutitas, C.G., 2004. Floating Breakwater Response to Waves Action Using a Boussinesq Model Coupled with a 2DV Elliptic Solver. Journal of Waterway, Port, Coastal 
and Ocean Engineering, 243-255.

Mohamed, R.G., 2006 Analysis of $\Pi$ shaped floating breakwater in oblique waves: I. Impervious rigid wave boards. Applied Ocean Research 28, 327-338.

Rahman, M.A., Mizutani,N., Kawasaki,K., 2006. Numerical modeling of dynamic responses and mooring forces of submerged floating breakwater. Coastal Engineering 53 (10), 799-815.

Shih, R.S., 2010. Experimental study on the performance characteristics of porous perpendicular pipe breakwaters. Ocean Engineering 50, 53-62.

Tang, H.J., Huang, C.C., Chen, W.M., 2011. Dynamics of dual pontoon floating structure for cage aquaculture in a two-dimensional numerical wave tank. Journal of Fluids and Structures 27, 918-936.

Williams, A.N., Abul-Azm, A.G., 1997. Dual pontoon floating breakwater. Ocean Engineering 24 (5), $465-478$.

Wang, H.Y., Sun, Z.C.. 2010. Experimental study of a porous floating breakwater. Ocean Engineering 37, $520-527$.

Wei P, Lee K.H., Shin S.H., Norimi M., 2013. Numerical simulation of interactions between water waves and inclined-moored submerged floating breakwaters. Coastal Engineering 82, 76-87. 


\section{Figures}

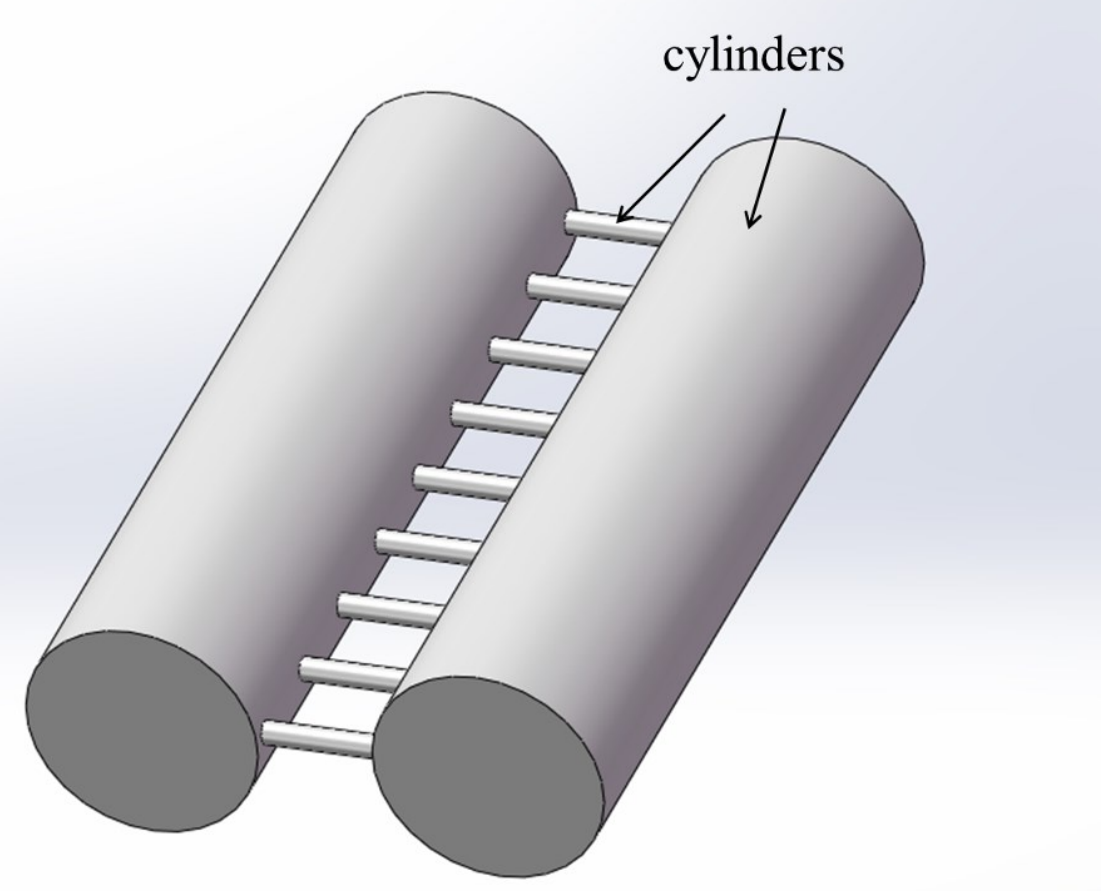

Fig. 1 Structure of Model 1: the cylindrical FB

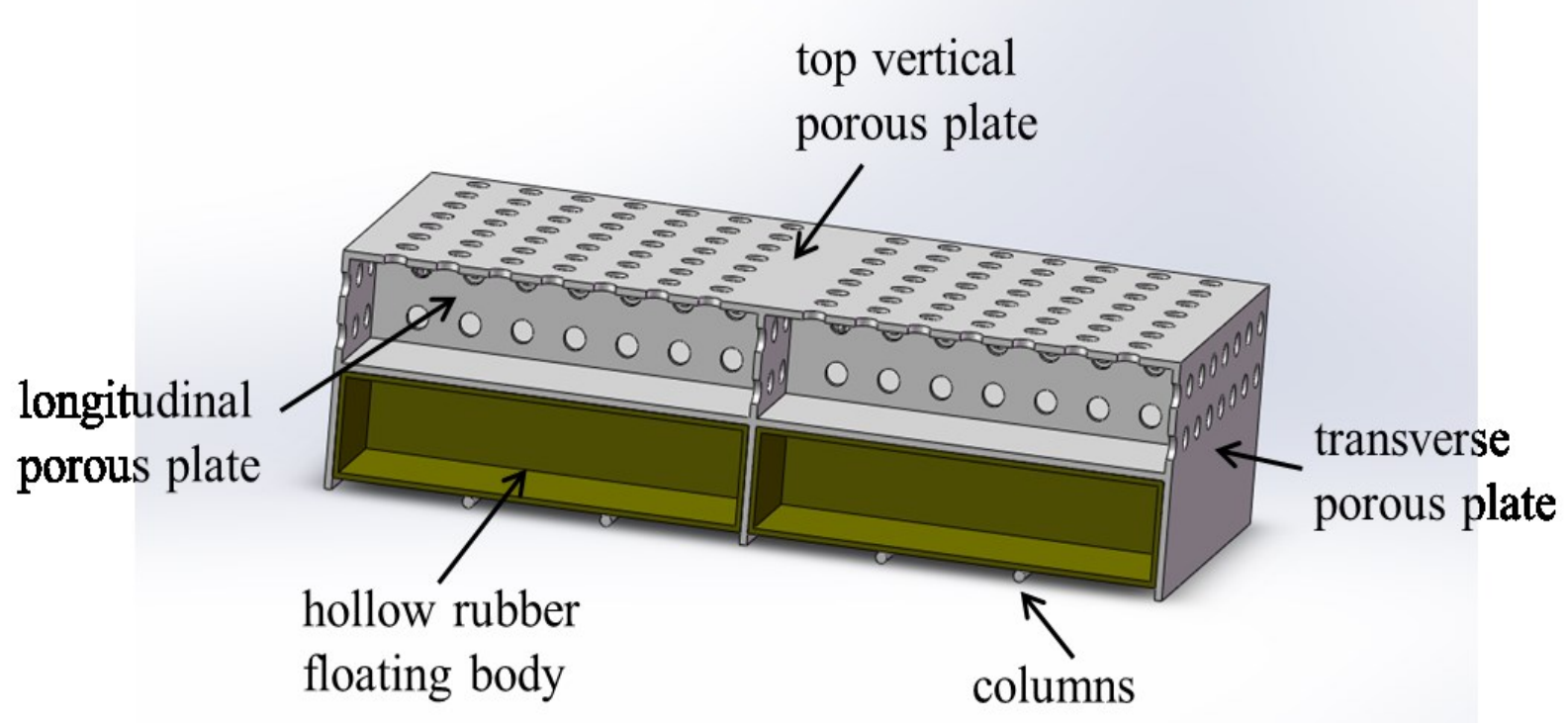

Fig. 2 Cross section of Model 2: the porous FB 


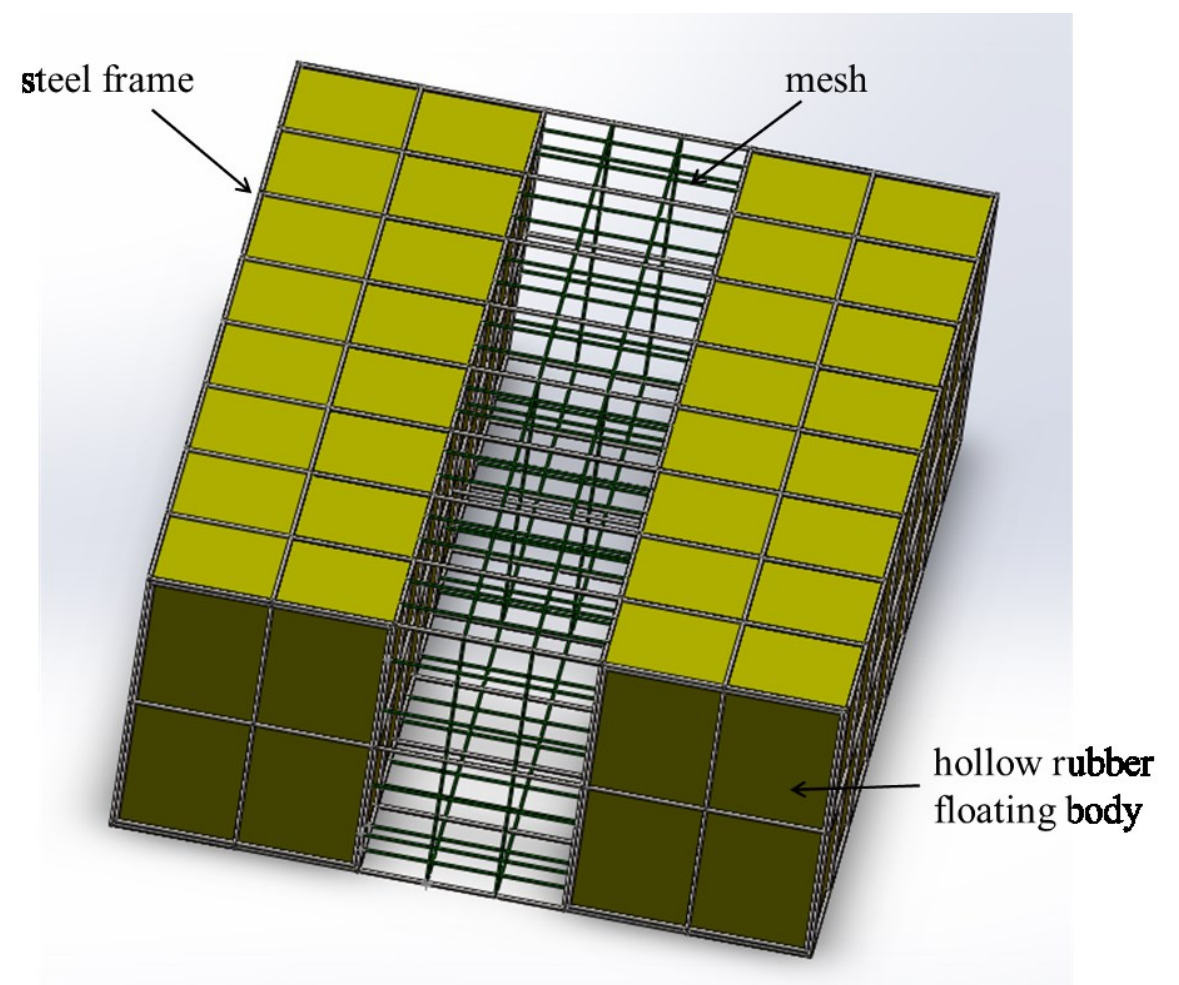

Fig. 3 Structure of Model 3: the mesh cage FB type-I

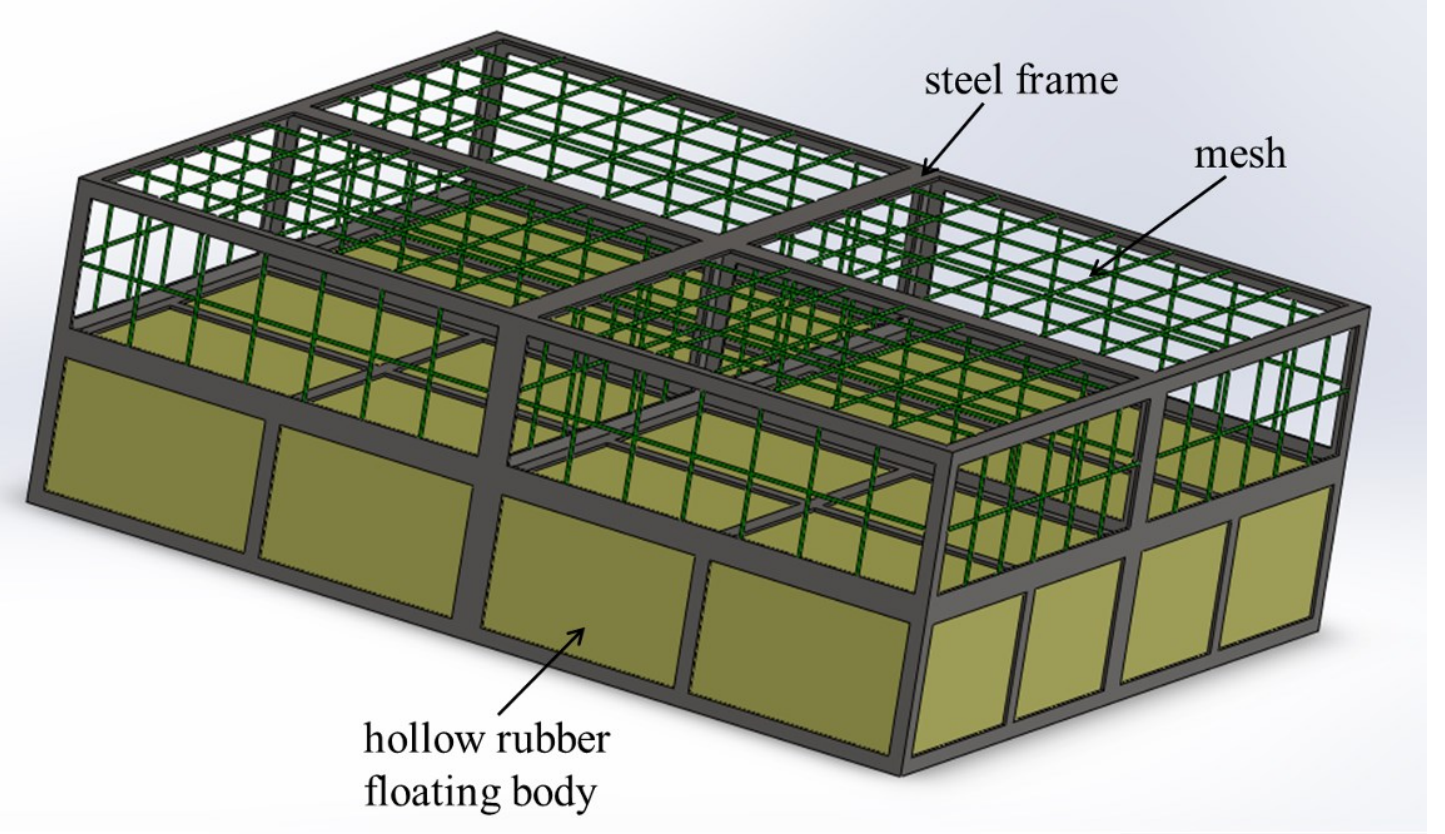

Fig. 4 Structure of Model 4: the mesh cage FB type- $\Pi$ 


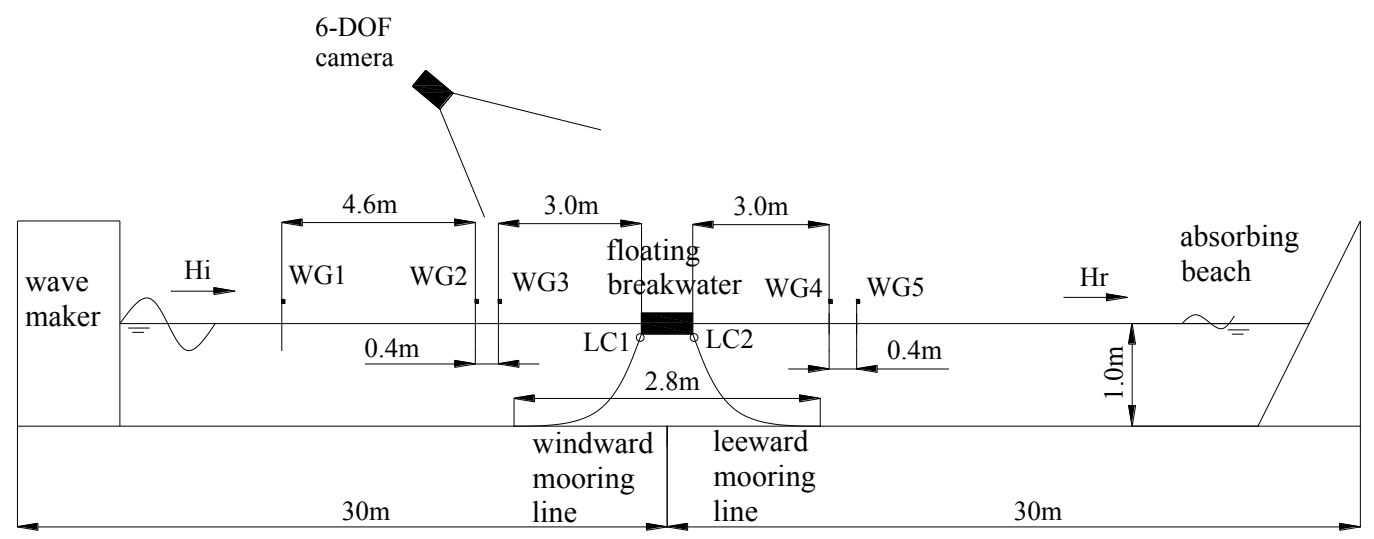

Fig. 5 Floating breakwater installation in the flume
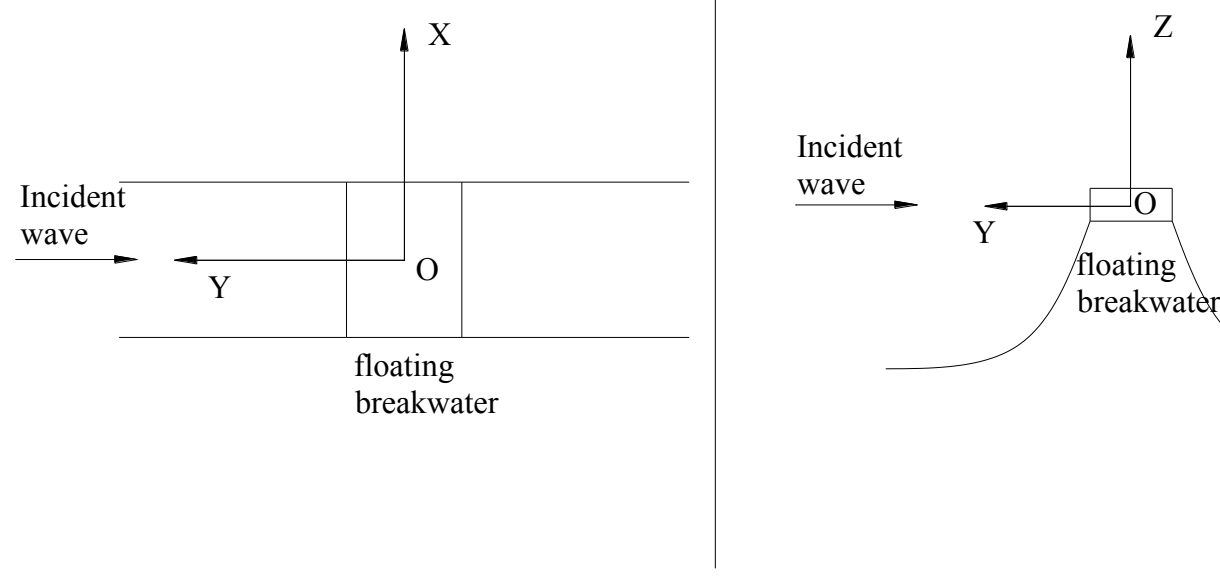

Fig. 6 The coordinate system of breakwater 

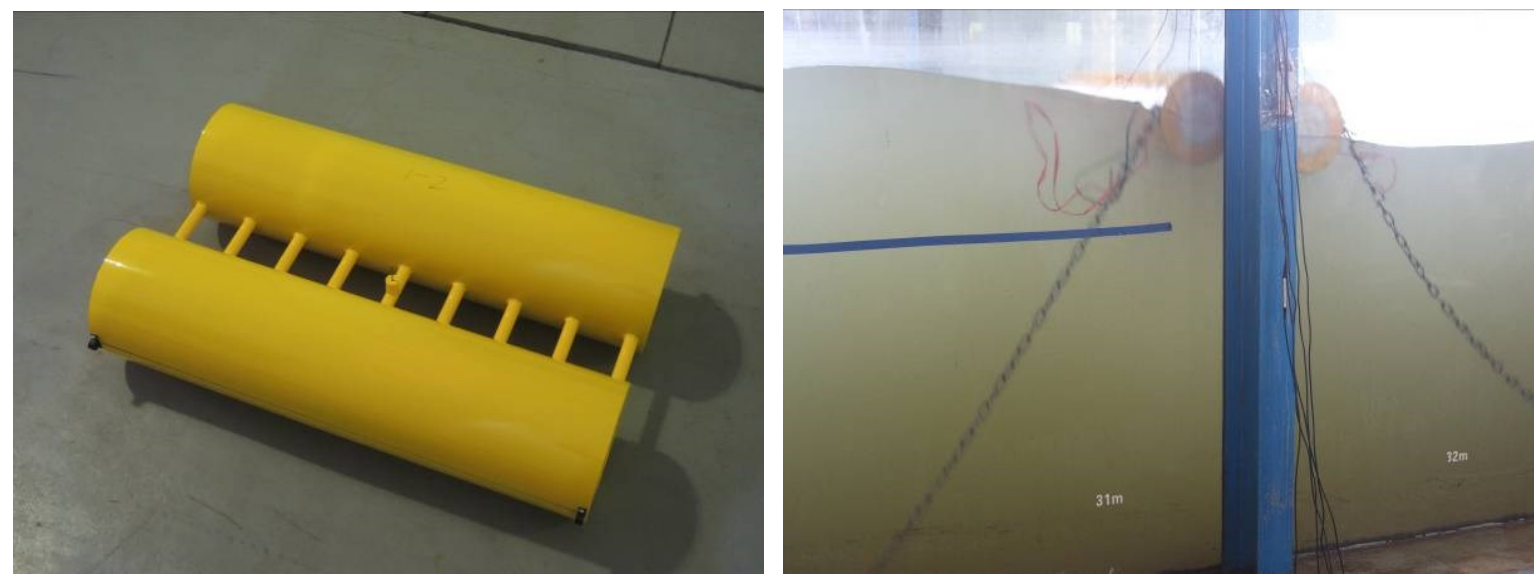

Fig. 7 Model 1
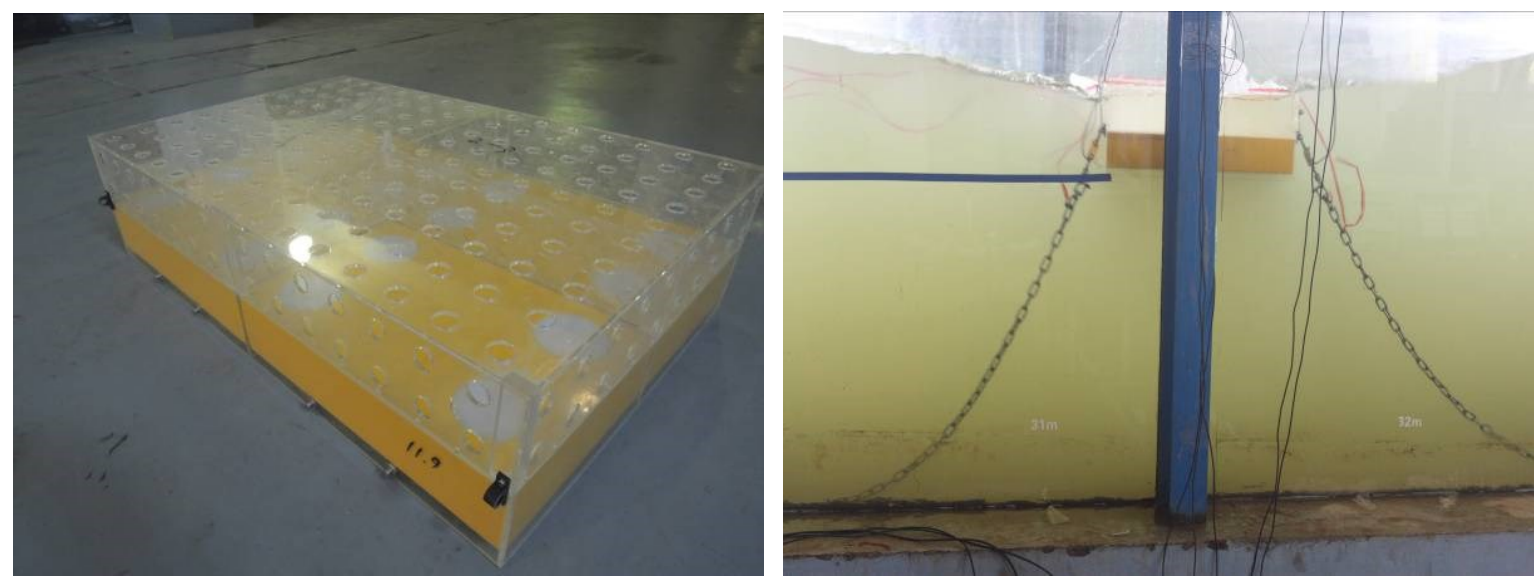

Fig. 8 Model 2
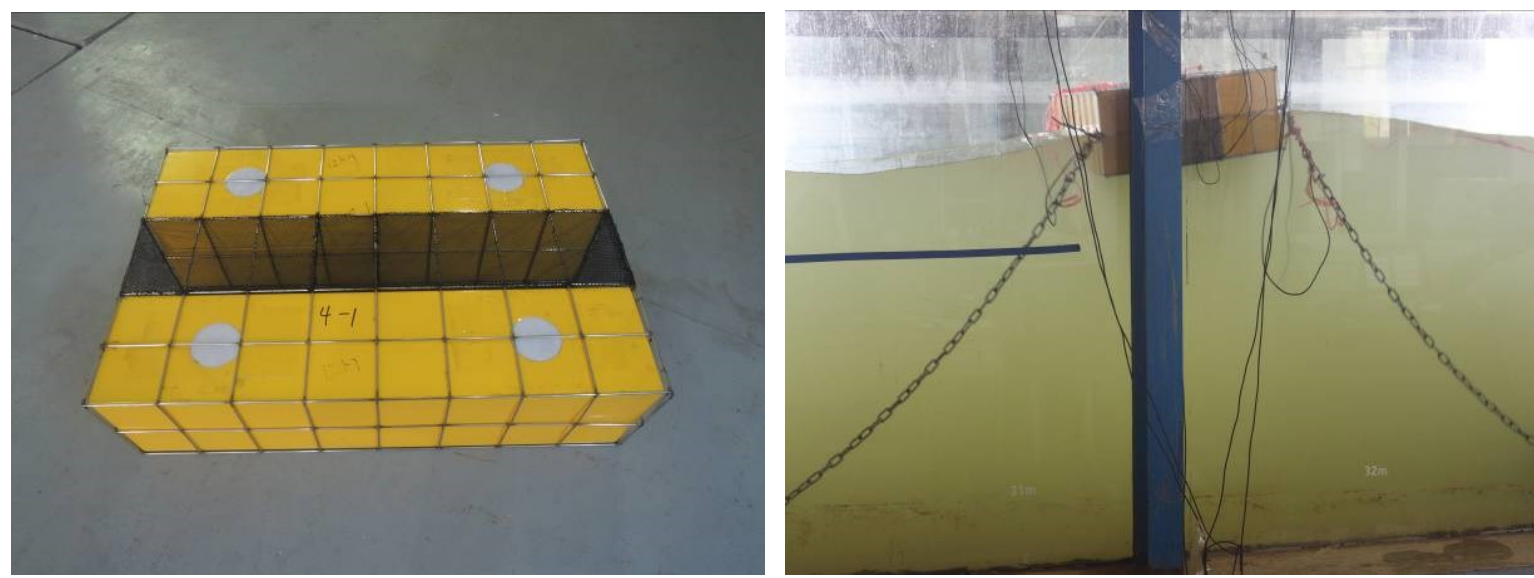

Fig. 9 Model 3 

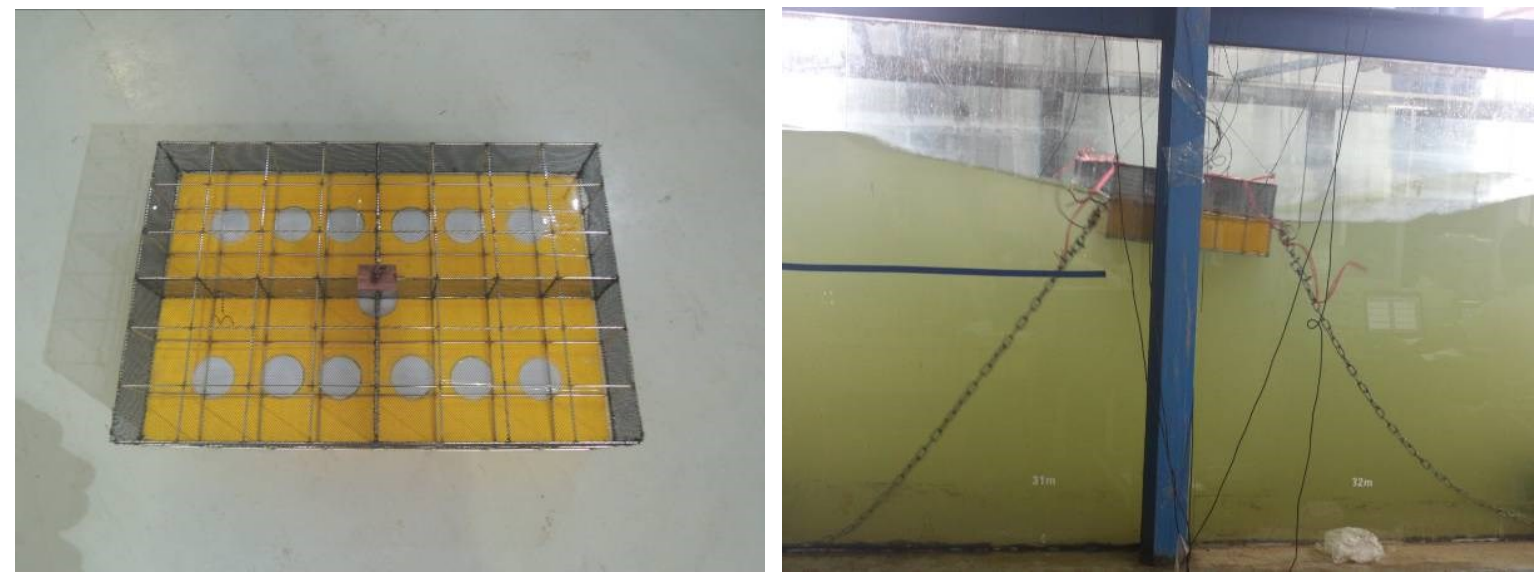

Fig. 10 Model 4

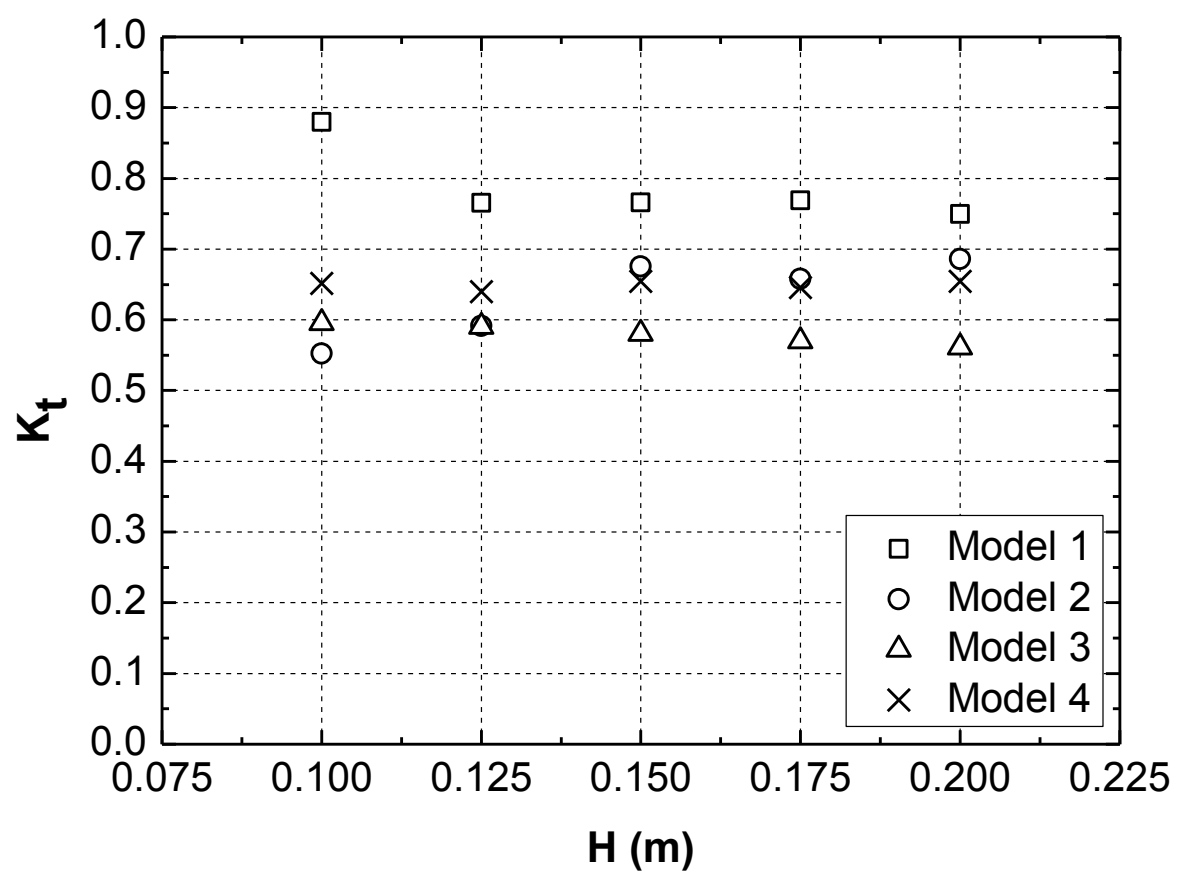

Fig. 11 Transmission coefficients of the four models $(\mathrm{T}=1 \mathrm{~s})$ 


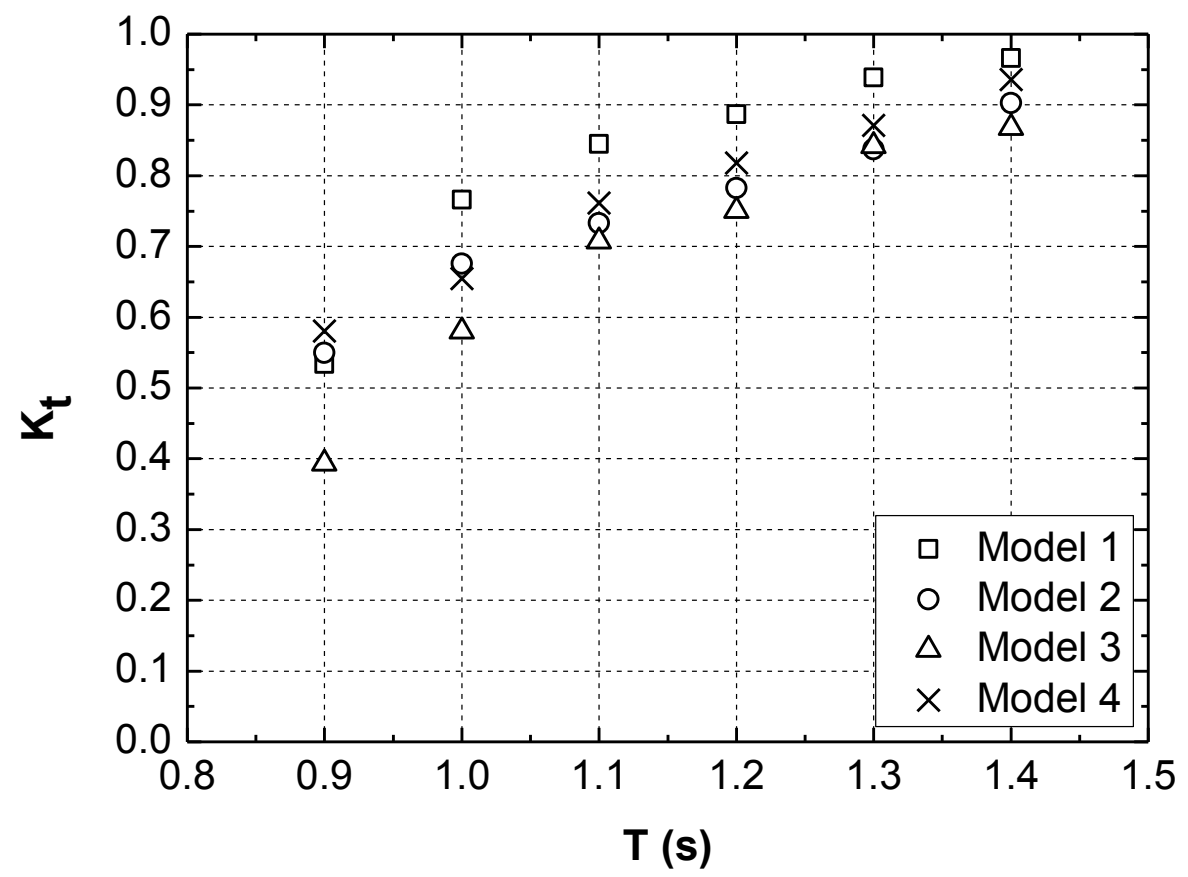

Fig. 12 Transmission coefficients of the four models $(\mathrm{H}=0.15 \mathrm{~m})$

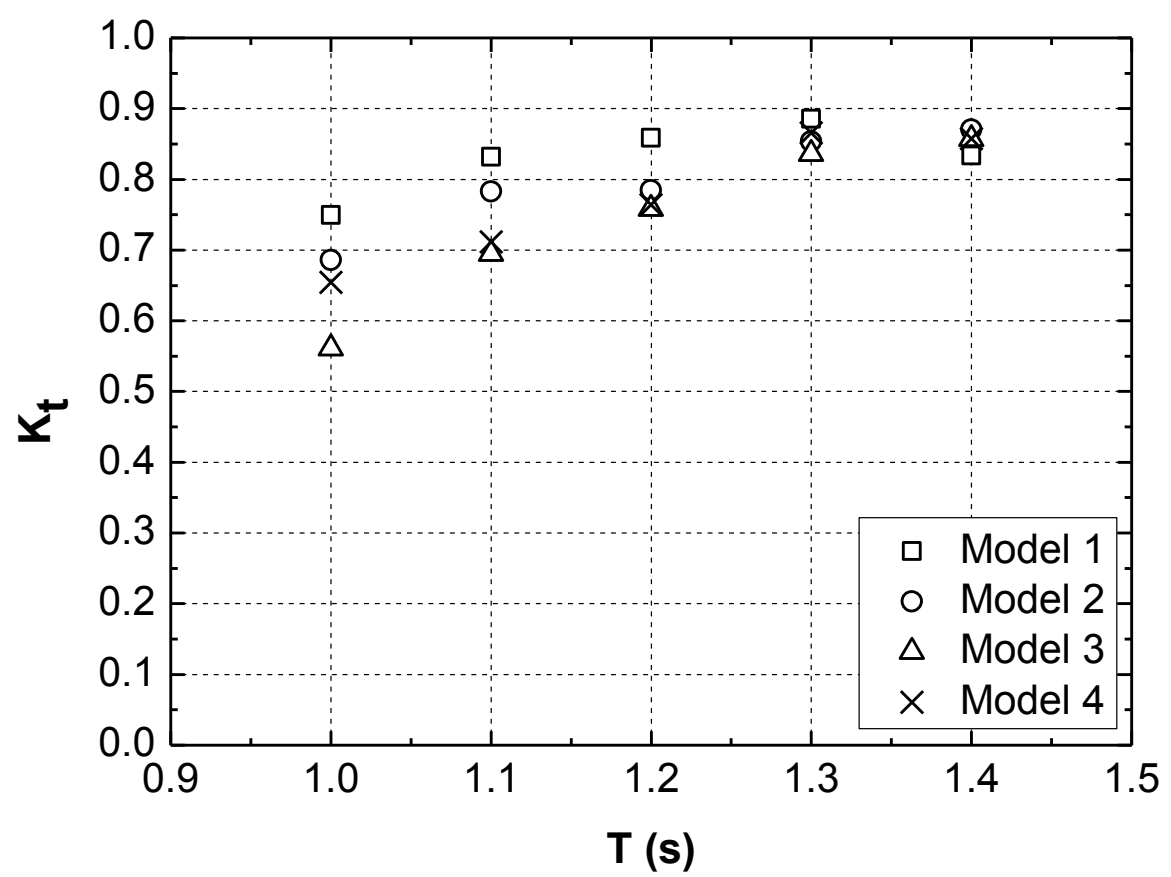

Fig. 13 Transmission coefficients of the four models $(\mathrm{H}=0.2 \mathrm{~m})$ 


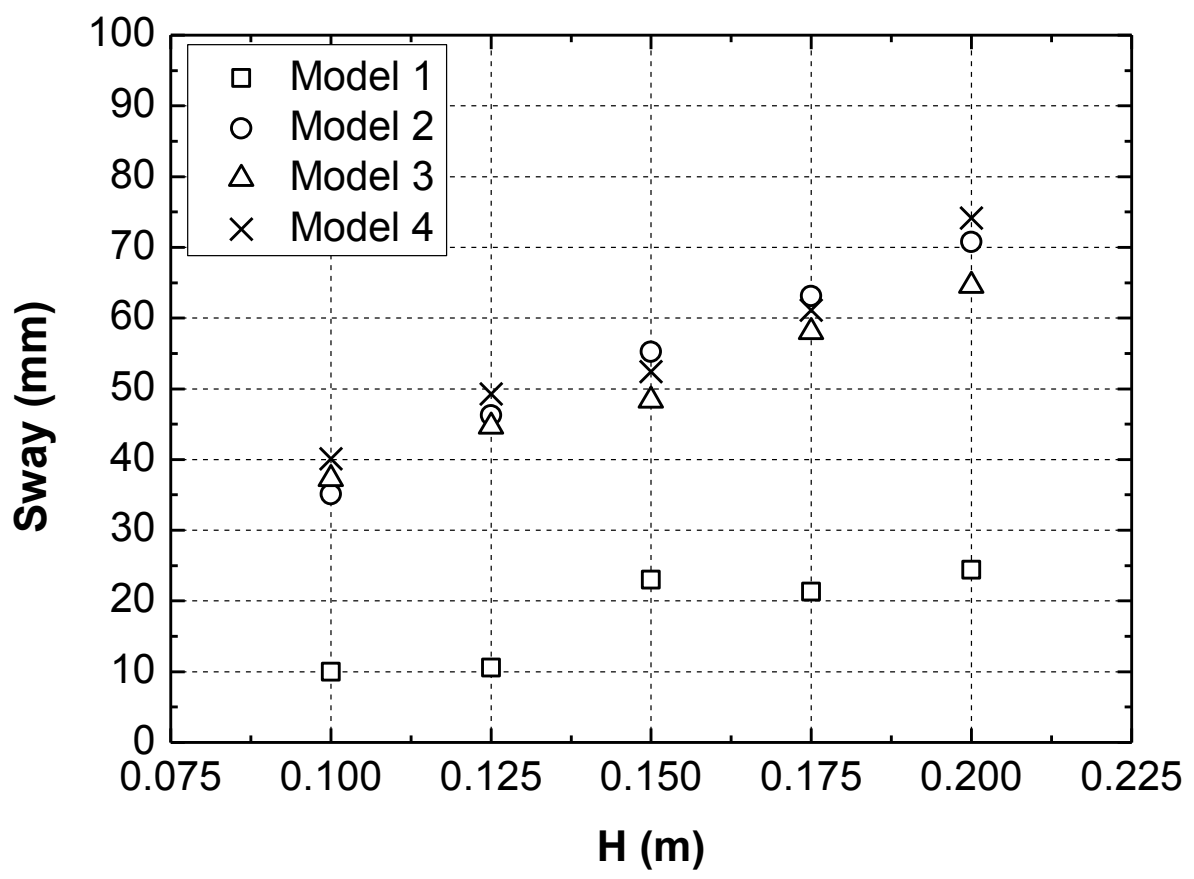

Fig. 14 Sway motion of the four models $(\mathrm{T}=1 \mathrm{~s})$

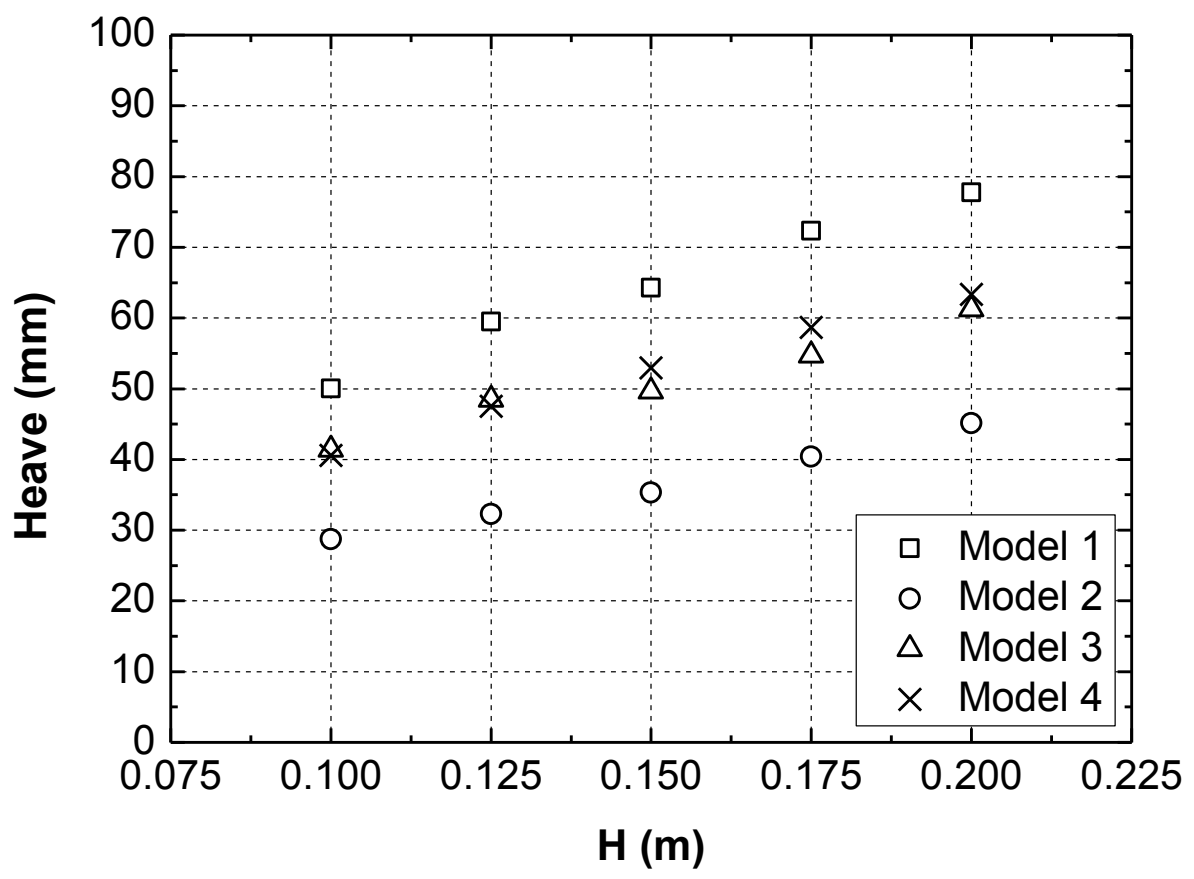

Fig. 15 Heave motion of the four models $(T=1 \mathrm{~s})$ 


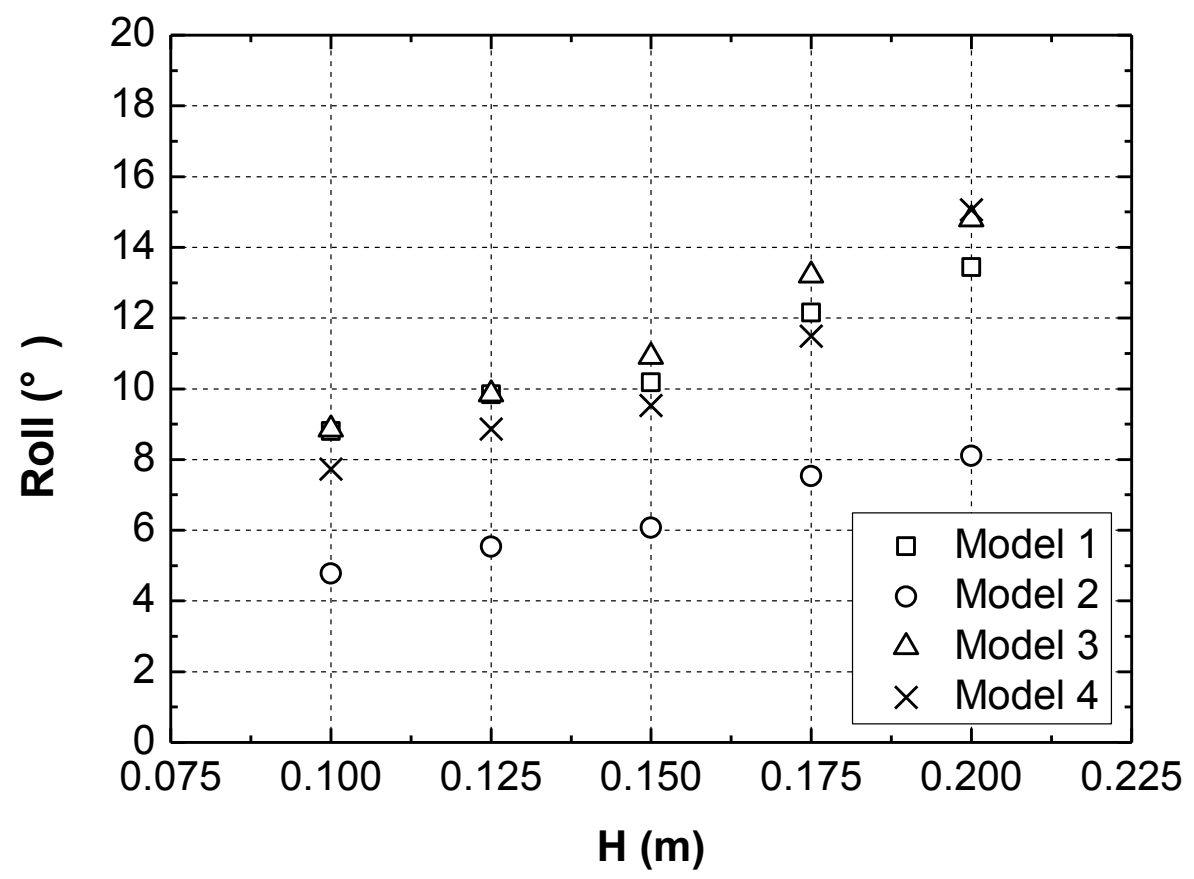

Fig. 16 Roll motion of the four models $(\mathrm{T}=1 \mathrm{~s})$

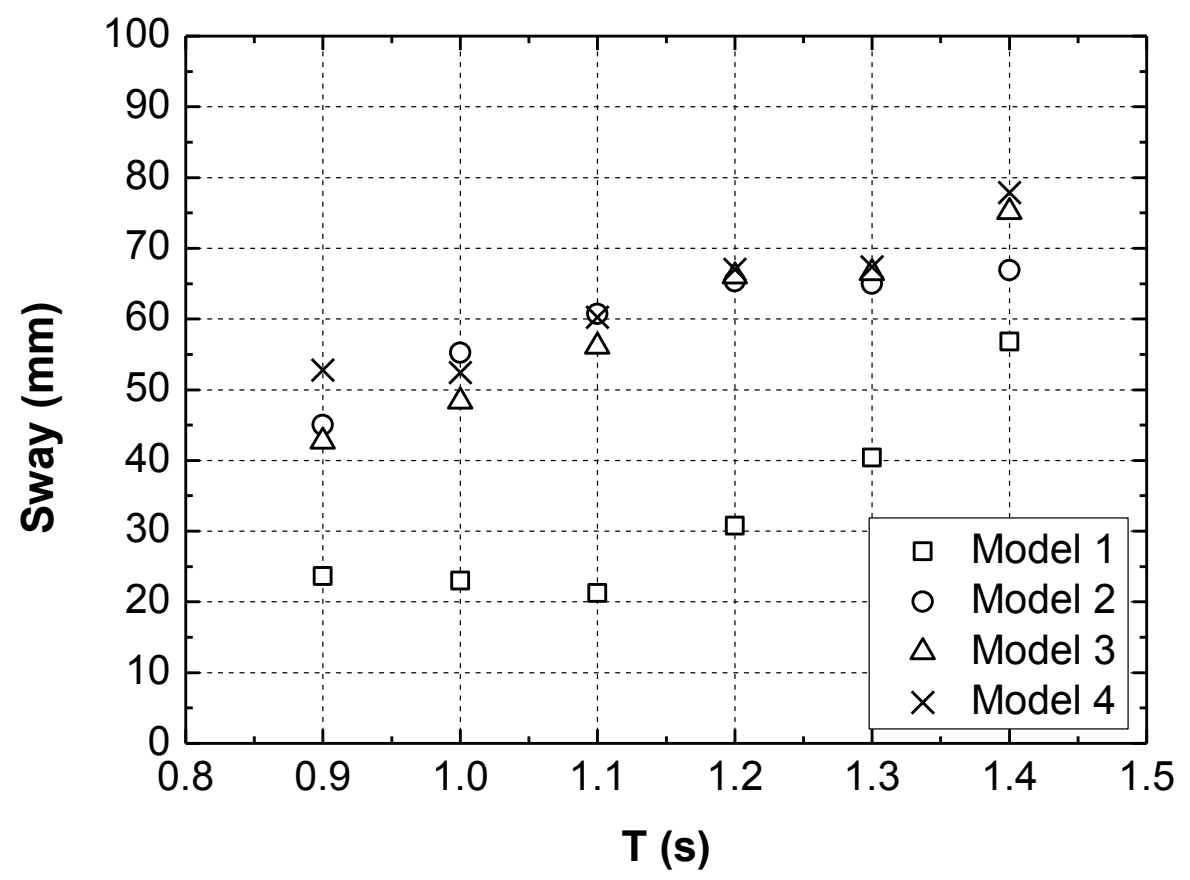

Fig. 17 Sway motion of the four models $(\mathrm{H}=0.15 \mathrm{~m})$ 


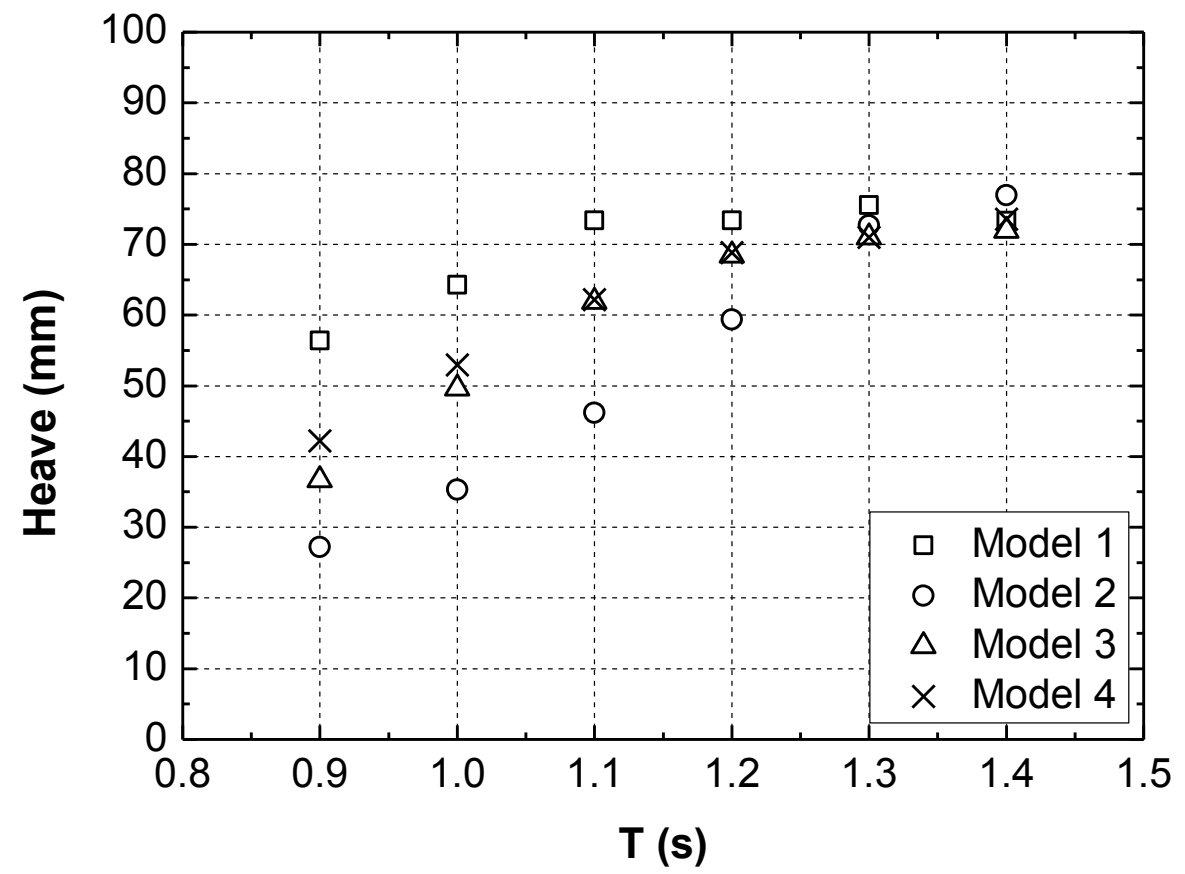

Fig. 18 Heave motion of the four models $(\mathrm{H}=0.15 \mathrm{~m})$

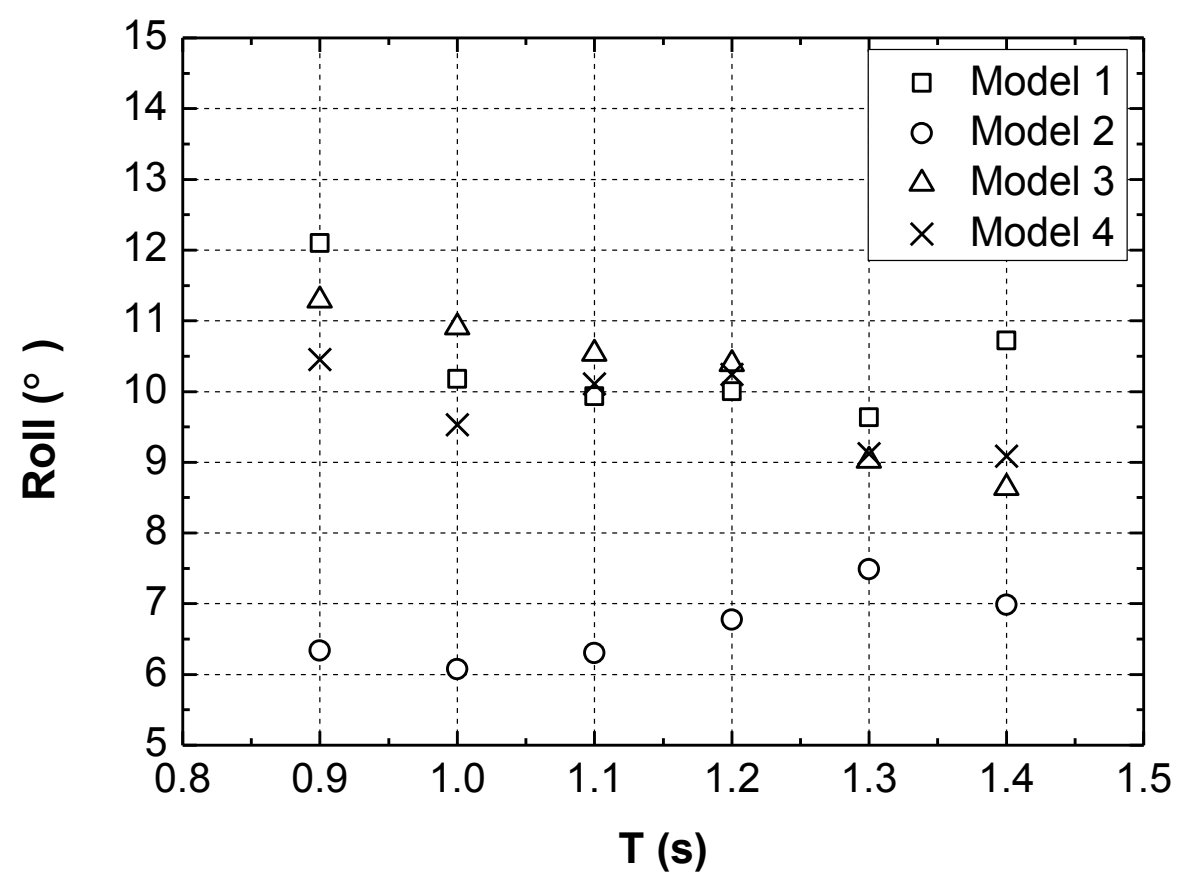

Fig. 19 Roll motion of the four models $(\mathrm{H}=0.15 \mathrm{~m})$ 


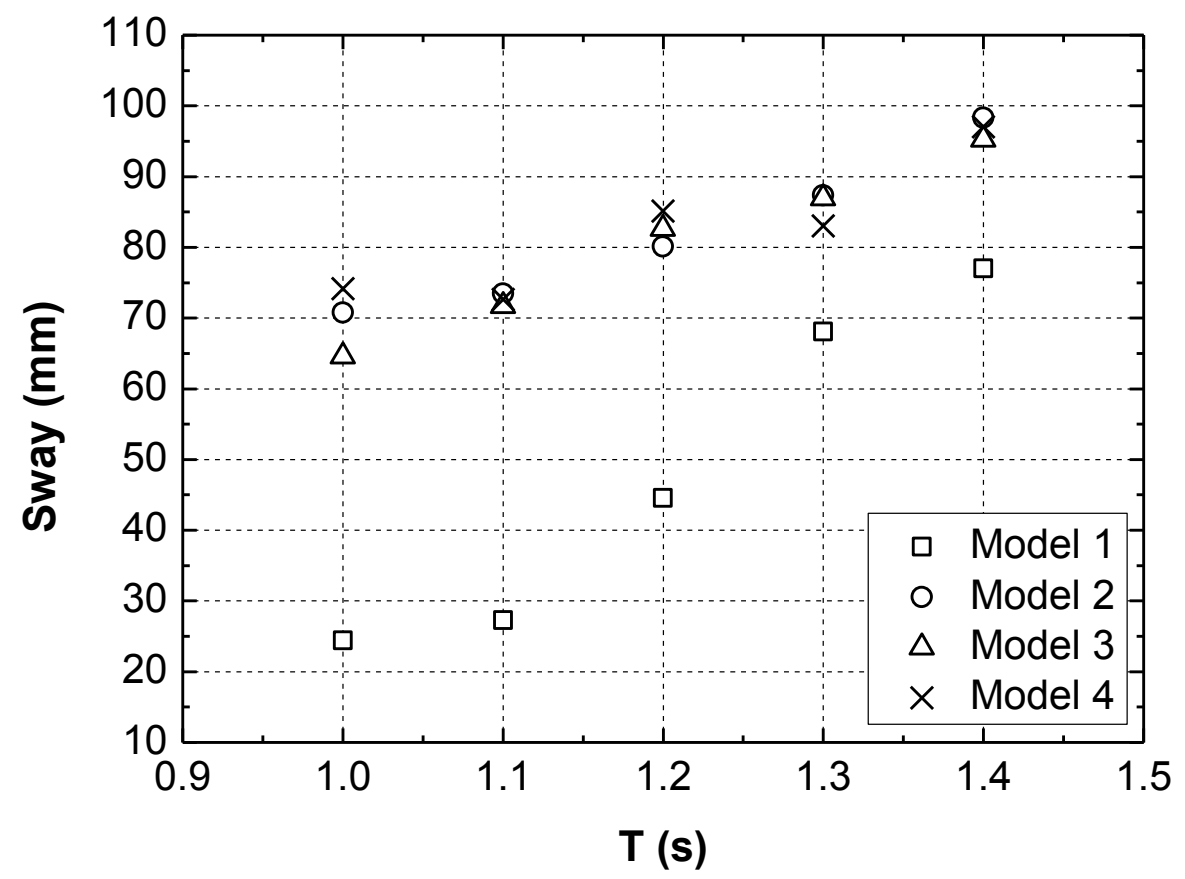

Fig. 20 Sway motion of the four models $(\mathrm{H}=0.2 \mathrm{~m})$

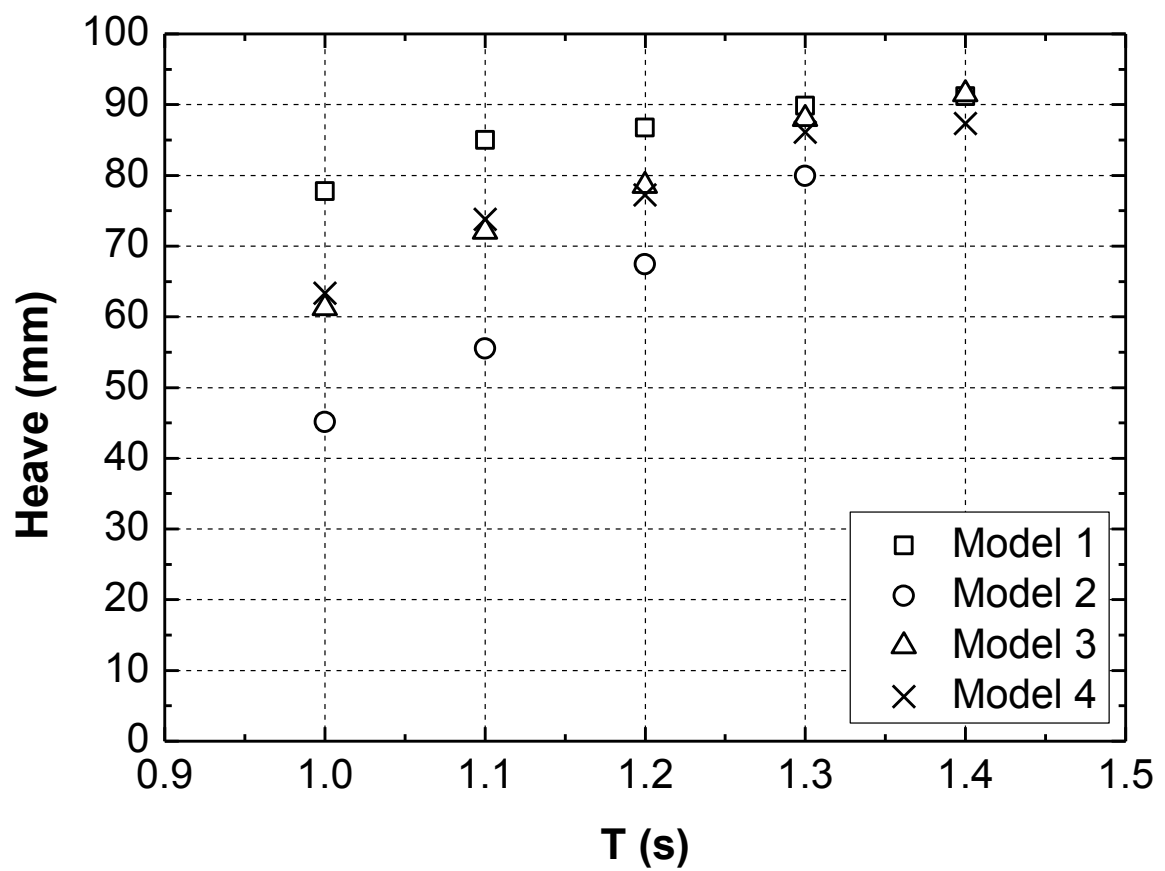

Fig. 21 Heave motion of the four models $(\mathrm{H}=0.2 \mathrm{~m})$ 


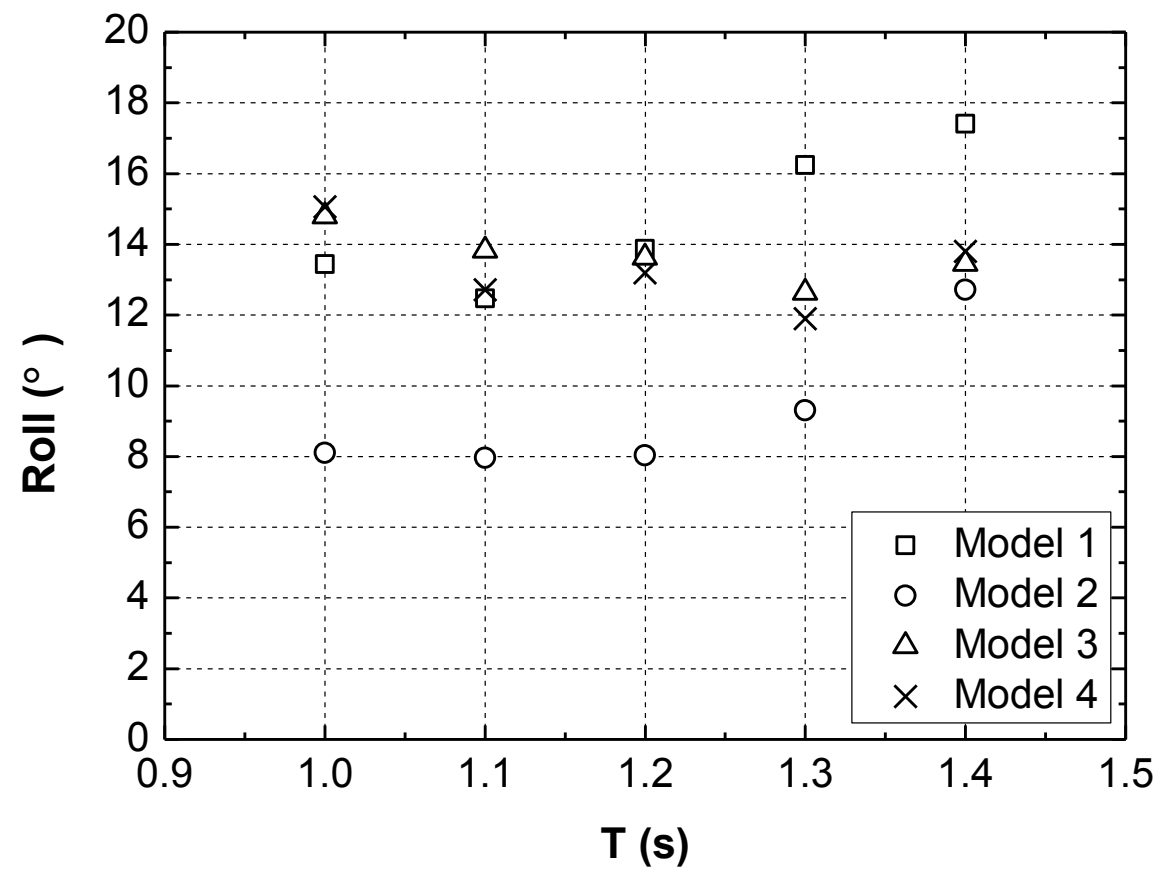

Fig. 22 Roll motion of the four models $(\mathrm{H}=0.2 \mathrm{~m})$

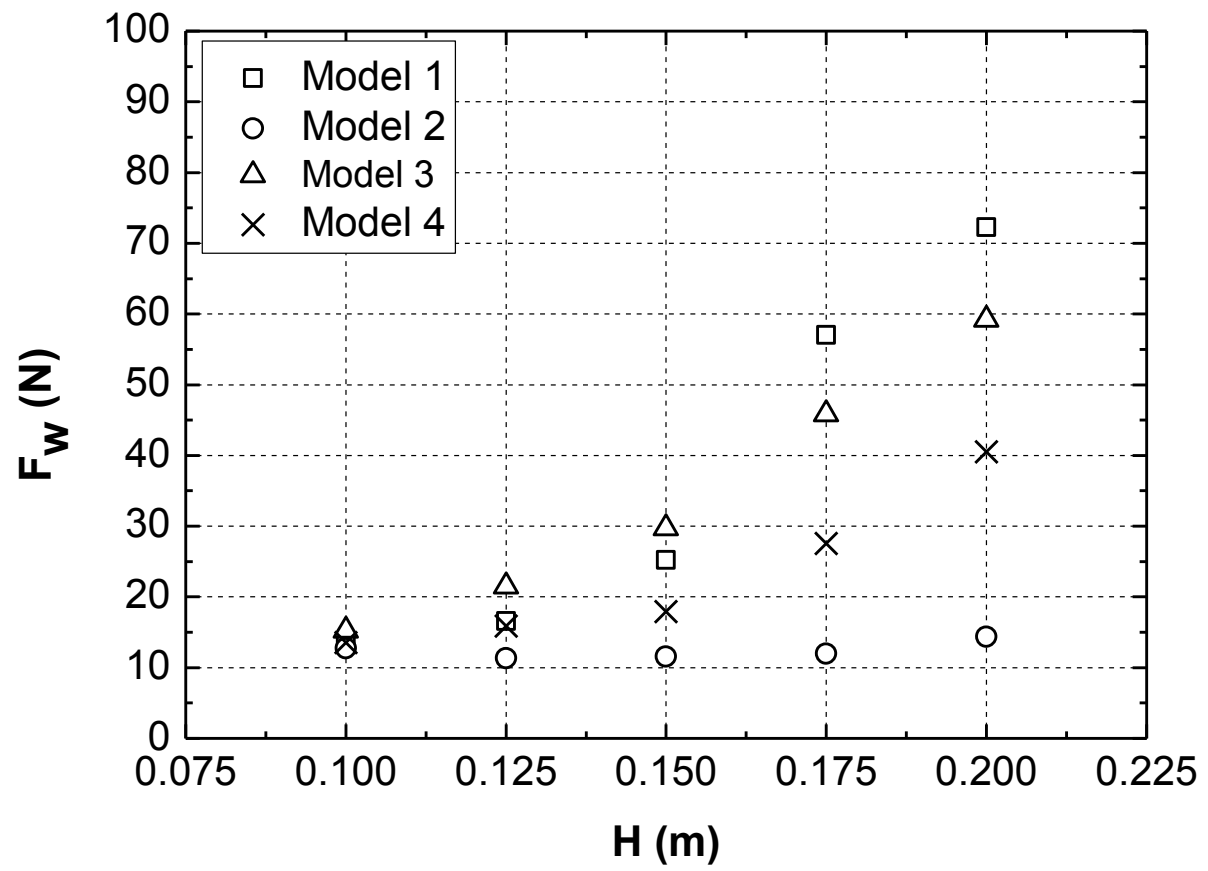

Fig. 23 Forces acting on the windward mooring lines of the four models $(\mathrm{T}=1 \mathrm{~s})$ 


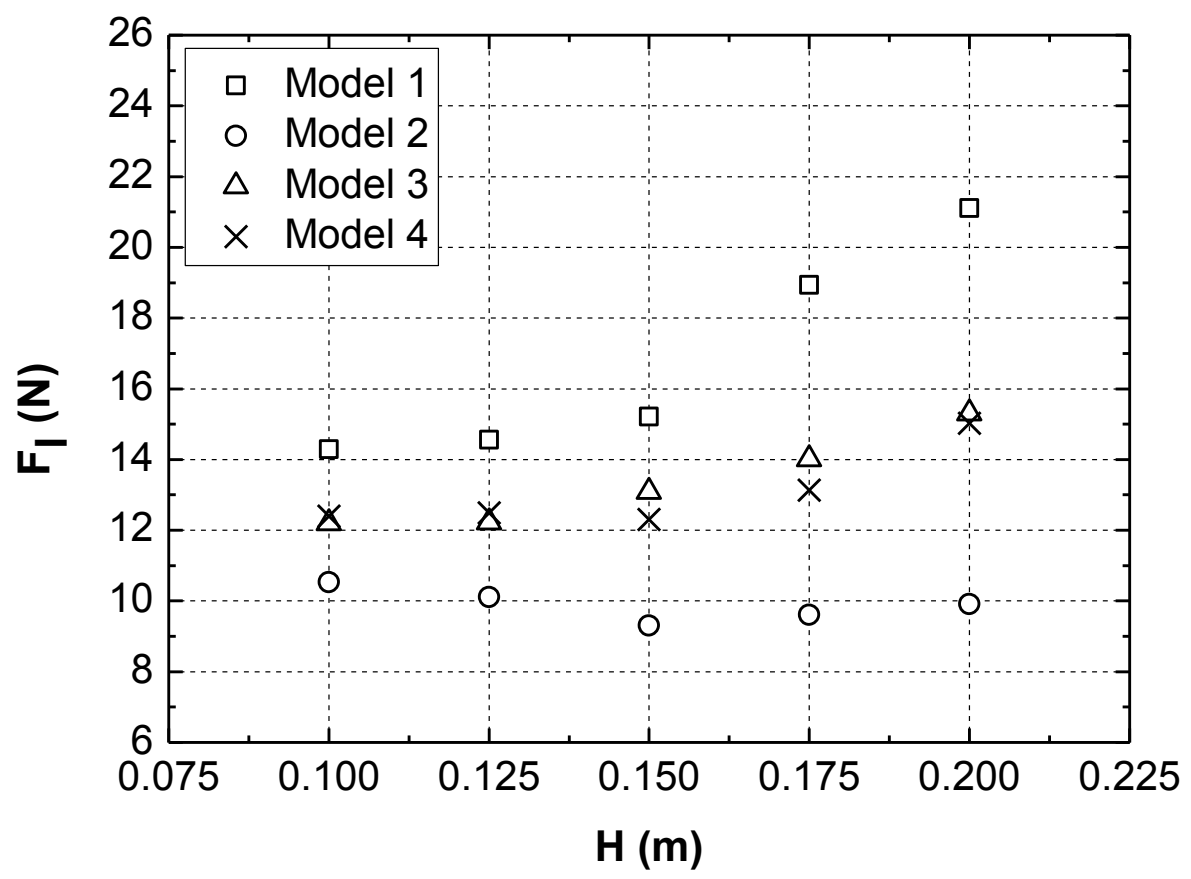

Fig. 24 Forces acting on the leeward mooring lines of the four models ( $T=1 \mathrm{~s})$

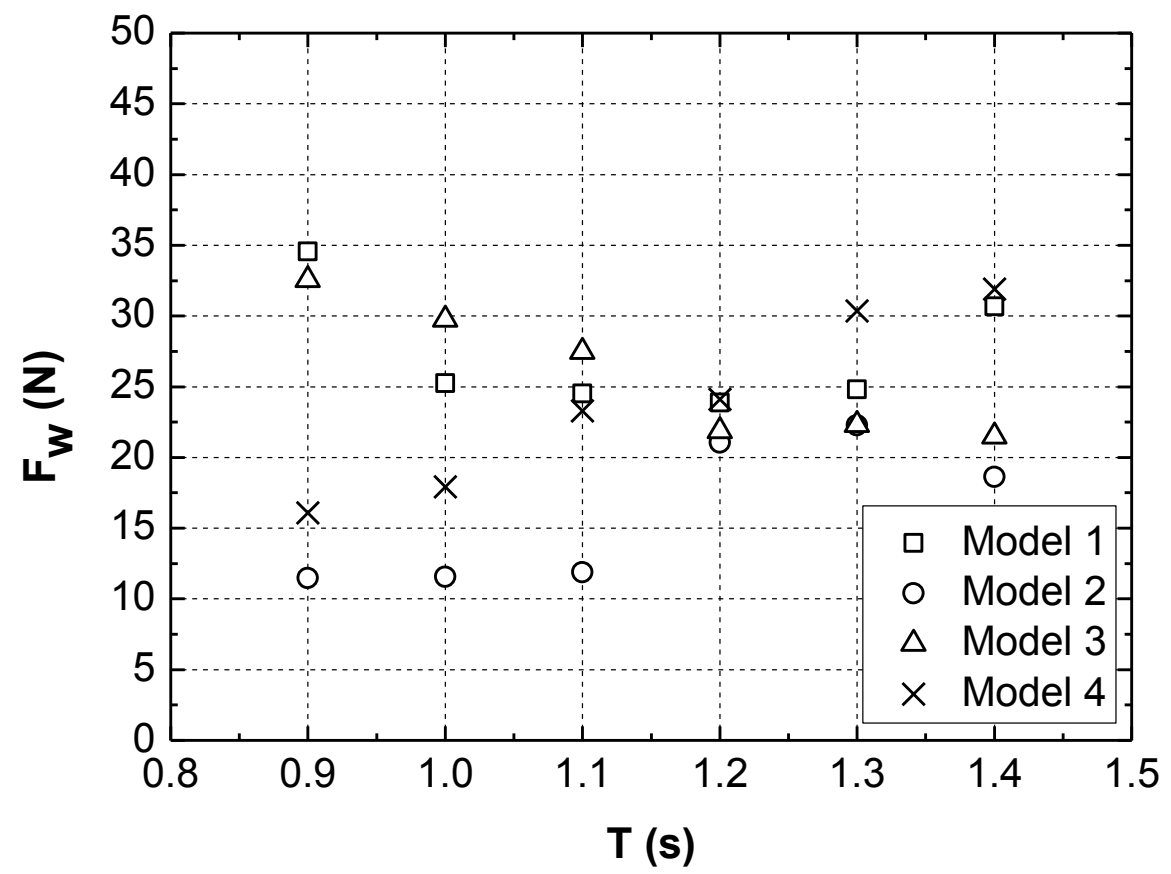

Fig. 25 Forces acting on the windward mooring lines of the four models $(\mathrm{H}=0.15 \mathrm{~m})$ 


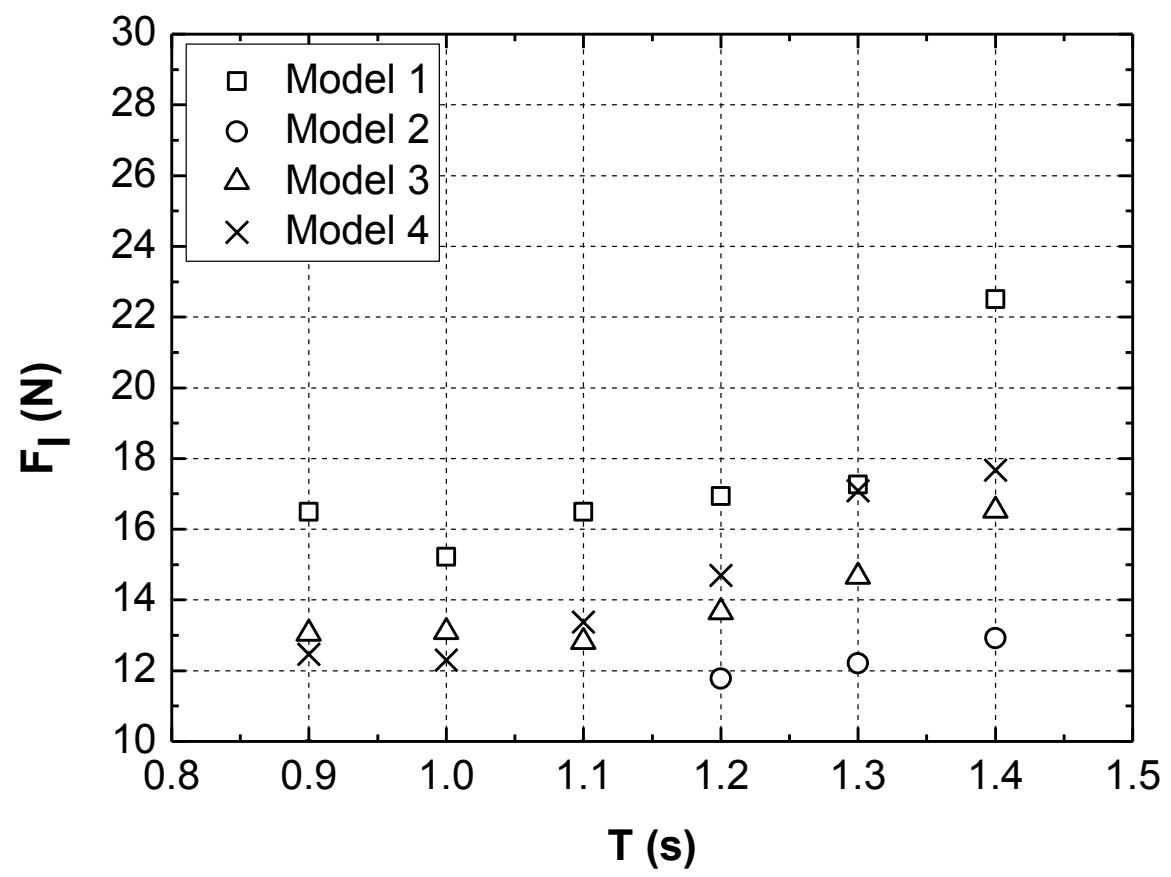

Fig. 26 Forces acting on the leeward mooring lines of the four models $(\mathrm{H}=0.15 \mathrm{~m})$

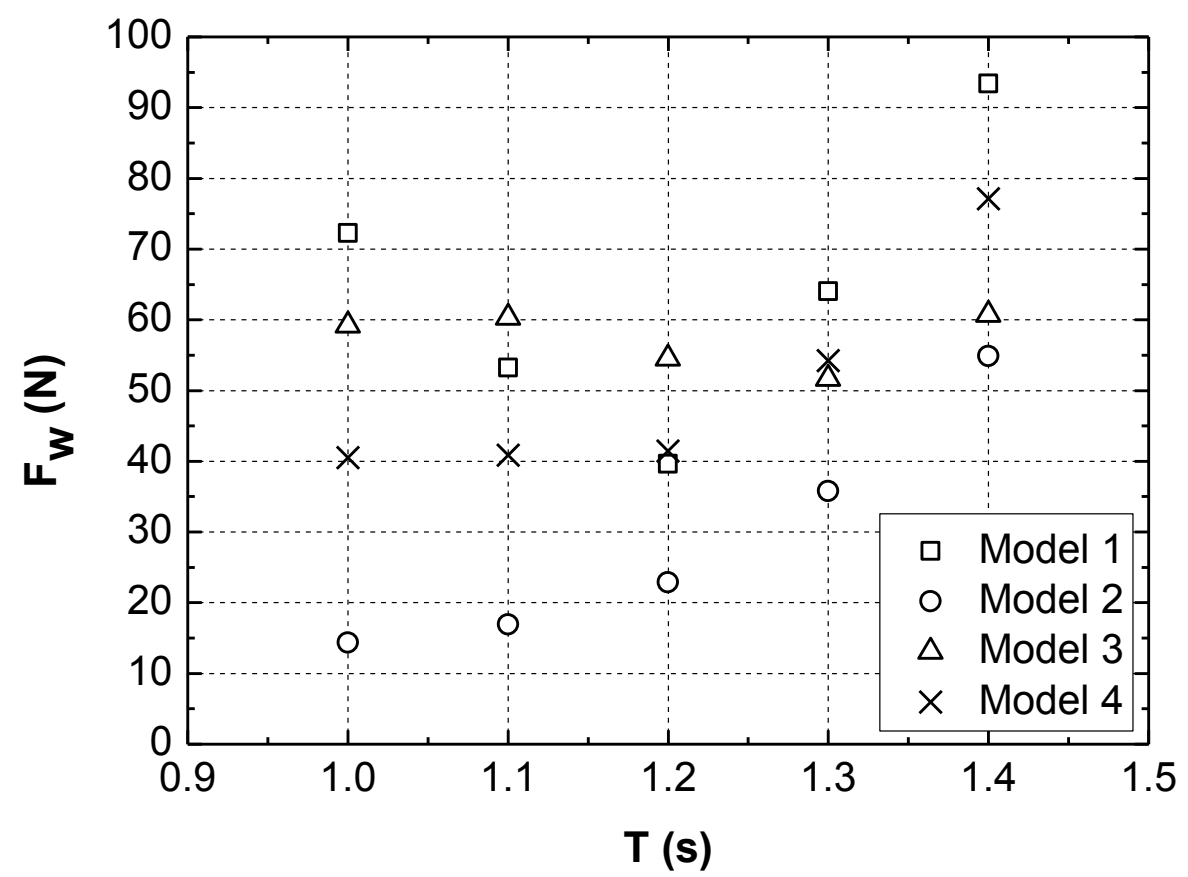

Fig. 27 Forces acting on the windward mooring lines of the four models $(\mathrm{H}=0.2 \mathrm{~m})$ 


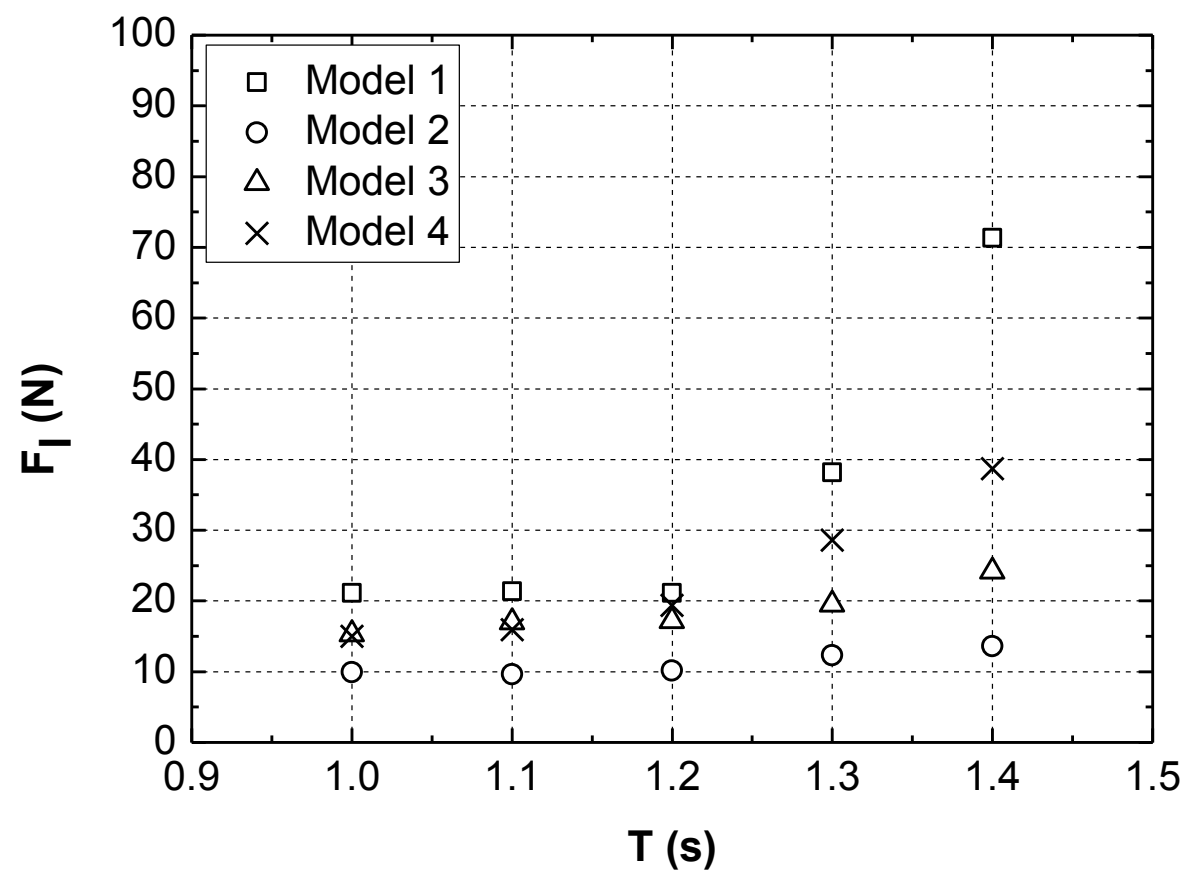

Fig. 28 Forces acting on the leeward mooring lines of the four models $(\mathrm{H}=0.2 \mathrm{~m})$ 


\section{Tables}

Table 1

Distances between wave gauges

\begin{tabular}{ll}
\hline Wave gauges & Distances $(\mathrm{cm})$ \\
\hline WG1 and WG2 & 460 \\
WG2 and WG3 & 40 \\
WG3 and WG4 & 650 \\
WG4 and WG5 & 40 \\
\hline
\end{tabular}

Table 2

Main parameters of four models

\begin{tabular}{llllllll}
\hline & $\begin{array}{c}\text { Length } \\
(\mathrm{mm})\end{array}$ & $\begin{array}{c}\text { Width } \\
(\mathrm{mm})\end{array}$ & $\begin{array}{l}\text { Height } \\
(\mathrm{mm})\end{array}$ & $\begin{array}{l}\text { Draught } \\
(\mathrm{mm})\end{array}$ & $\begin{array}{l}\text { Mass } \\
(\mathrm{kg})\end{array}$ & $\begin{array}{l}\text { Roll inertia } \\
\left(\mathrm{kg}^{*} \mathrm{~m}^{2}\right)\end{array}$ & $\begin{array}{l}\text { Gravity Center } \\
\text { above bottom }(\mathrm{mm})\end{array}$ \\
\hline Model 1 & 760 & 500 & 200 & 100 & 19.1 & 0.474 & 100 \\
Model 2 & 760 & 500 & 200 & 100 & 28.0 & 0.647 & 69 \\
Model 3 & 760 & 500 & 200 & 100 & 19.1 & 0.558 & 100 \\
Model 4 & 760 & 500 & 200 & 100 & 27.3 & 0.554 & 52 \\
\hline
\end{tabular}

Table 3

Experimental test conditions

\begin{tabular}{ll}
\hline $\mathrm{H}(\mathrm{m})$ & $\mathrm{T}(\mathrm{s})$ \\
\hline 0.1 & 1.0 \\
0.125 & 1.0 \\
0.15 & $0.9,1.0,1.1,1.2,1.3,1.4$ \\
0.175 & 1.0 \\
0.2 & $1.0,1.1,1.2,1.3,1.4$ \\
\hline
\end{tabular}

